Review Article

\title{
Understanding our Celestial Neighbors: An Indian Perspective in Planetary Sciences and Exploration
}

\author{
PRAKASH CHAUHAN ${ }^{1, *}$, ANIL BHARDWAJ ${ }^{2}$, P SENTHIL KUMAR $^{3}$, PRABHJOT KAUR $^{1}$ and \\ N BHANDARI ${ }^{4}$ \\ ${ }^{1}$ Space Applications Centre, Ahmedabad, India \\ ${ }^{2}$ Space Physics Laboratory, Vikram Sarabhai Space Centre, Thiruvananthapuram, India \\ ${ }^{3}$ CSIR-National Geophysical Research Institute, Hyderabad, India \\ ${ }^{4}$ Physical Research Laboratory, Ahmedabad, India
}

(Received on 18 May 2016; Accepted on 10 June 2016)

\begin{abstract}
The planetary exploration program of the Indian Space Research Organization is described. The important results obtained from the two successful missions, Mars orbiter Mission (2014) and the earlier Chandrayaan-1 mission (2008-9) to moon are summarized. High-resolution maps of Valles Marineris enabled several surface, aqueous and atmospheric features to be delineated and the highly elliptical orbit of MOM enabled imaging of the surface of the farther side of Deimos as well as study of Mars exospheric constituents. The results from Chandrayaan-1 mission changed many lunar concepts e.g. from dry, passive and inactive to moon to wet, tectonically and volcanically active moon. Some recent results based on the space borne and laboratory based study of Titan, Pluto, Comets and meteorites coming from Mars and Vesta are summarized. The future planetary exploration plans, such as Chandrayaan-2 and second Mars mission are briefly mentioned.
\end{abstract}

Keywords: Planetary Science; Mars Orbiter Mission; Moon; Mars; Asteroids; Chandrayaan-2

\section{Introduction}

The scientific study of the Moon and Mars, and other planetary bodies, is being carried out for variety of aspects, which provide insight into various geological, atmospheric, solar wind and solar radiation interaction processes operating in their environment. In India, planetary exploration gained momentum with the launch of first Indian planetary mission Chandrayaan-1 in 2008. Chandrayaan-1 orbiter explored the lunar surface and its environment with eleven instruments and the plethora of data returned by the spacecraft have provided much new information and led to many new discoveries related to lunar surface processes. Many researchers are still analyzing Chandrayaan-1 data and in the last four years many new scientific findings have been reported by Indian and foreign planetary scientists based on Chandrayaan-1 observations. These include discovery of water signature, spinel minerals, lunar lava tubes, evidences of recent volcanism, impact-triggered boulder movements (Arya, et al., 2011; Bhattacharya, et al., 2012a; 2013, 2015a; Chauhan, et al., 2014; Kaur, et al., 2012; 2013a\&b, 2014; Kumar, et al., 2016; Lal et al. 2012; Srivastava and Gupta, 2012, 2013), discovery of sputtered atomic oxygen and backscattered helium (Vorburger et al., 2104), and many new results on lunar energetic neutral atoms (ENAs) and lunar plasma wake (Bhardwaj and Mukundan, 2015; Dhanya et al., 2013, 2016). Lunar scientists in India are also gearing up for the upcoming landing mission to Moon- Chandrayaan-2, which will have an orbiter, lander and rover configuration. The Chandrayaan-2 mission is scheduled to be launched in 2017-18 timeframe.

During the last four years, the biggest excitement for Indian planetary community was the successful launch of the first Indian Mission to Mars - Mars Orbiter Mission (MOM). The MOM with five instruments was launched from Sriharikota using an expanded version of Polar Satellite Launch Vehicle

*Author for Correspondence: E-mail: prakash@sac.isro.gov.in 
(PSLV-XL) rocket on November 5, 2013. MOM is currently working fine and orbiting around Mars in an elliptical orbit. The instruments onboard MOM are Mars Colour Camera (MCC), Methane Sensor for Mars (MSM), Thermal Infra-Red Imaging Spectrometer (TIS), Mars Exospheric Neutral Composition Analyzer (MENCA), and Lyman-Alpha Photometer (LAP). The details of these instruments are described in a series of recently published papers (Arya et al., 2015a; Bhardwaj et al., 2015a; Mathew et al., 2015; Singh et al., 2015; Sridhar et al., 2015).

Table 1 provides the summary of the instrument on-board Mars Orbiter Mission. These five instruments on-board MOM are providing information about the atmosphere-exosphere and surface of Mars. The wealth of data obtained by MOM is being analyzed by various Indian scientists to understand the geologic, climatic and atmospheric processes occurring on Mars.

These two planetary missions of ISRO have greatly helped Indian scientific community to explore, learn and work in planetary sciences. This paper is intended to provide summary of scientific studies carried out mainly by Indian researchers related to the planetary science field - especially Moon and Mars, but also cover studies done on other bodies in the solar system, e.g. Venus, Comets, Titan, Pluto, and laboratory based studies of Vestan meteorites which fell in India.

\section{Exploration of Mars Through the First Indian Mars Orbiter Mission and other International Data Sets}

The data provided by MOM missions has mainly been used to study surface of Mars and its atmosphere. Martian dust patterns in lower atmosphere and dust storms around high altitude regions were studied using Mars Color Camera (MCC) (Mishra et al., 2016; Singh and Mishra, 2016). Albedo of the Martian surface using the $1.65 \mu \mathrm{m}$ channel of Methane sensor for Mars (MSM) was also estimated (Singh and Mishra, 2016). Far side of Deimos, the smaller moon of Mars, was imaged by MCC (Arya et al., 2015b), which has not been viewed by any Mars orbiter in the recent time. Mineralogical studies using hyperspectral data enabled the identification of different minerals like sulphates and ferrous based compounds on the surface of Mars (Jain and Chauhan, 2015a), leading to the understanding of the aqueous history of Mars. MENCA instrument onboard MOM provided interesting results about the evening exosphere of Mars (Bhardwaj et al., 2016). Glacial/ periglacial landforms which are geologic and climatic indicators have also been explored by Indian researchers to understand the climatic history of planet Mars (Sinha and Murty 2013a,b; 2015). Details of these observations are summarized below.

\section{Martian Surface and Atmosphere}

Martian surface is extremely dynamic where dust storms and dust devils are common phenomena occurring during the change of seasons. These dust storm and dust devils are well captured in Mars Color

Table 1: Summary of scientific payloads on-board Mars Orbiter Mission

\begin{tabular}{|c|c|c|c|}
\hline Payload & Science theme & Mass $(\mathrm{kg})$ & Power $(\mathrm{W})$ \\
\hline $\begin{array}{l}\text { Methane Sensor for Mars (MSM): Measures radiance within } \\
\text { extremely narrow absorption lines of } \mathrm{CH}_{4}\end{array}$ & $\begin{array}{l}\text { Measurement of methane } \\
\text { with high accuracy }\end{array}$ & 2.94 & 7.5 \\
\hline $\begin{array}{l}\text { Thermal Infrared Imaging Spectrometer (TIS): A TIR } \\
\text { Spectrometer }(7 \mu \mathrm{m}-13 \mu \mathrm{m}) \text {, Min. } 12 \text { bands }\end{array}$ & $\begin{array}{l}\text { Temperature mapping of } \\
\text { Martian surface }\end{array}$ & 3.2 & 6 \\
\hline Mars Colour Camera (MCC) : RGBframe camera & $\begin{array}{l}\text { Morphological features, Visual } \\
\text { images of Mars and its environs, } \\
\text { context information for other payloads }\end{array}$ & 1.3 & 3 \\
\hline $\begin{array}{l}\text { Mars Exospheric Neutral Composition Analyzer (MENCA): } \\
\text { Quadrupole Mass Spectrometer }\end{array}$ & $\begin{array}{l}\text { Measurement of neutral composition } \\
\text { and total pressure in Martian upper } \\
\text { atmosphere-exosphere }\end{array}$ & 3.56 & $\begin{array}{l}2947 \\
(\text { degas } \\
\text { mode) }\end{array}$ \\
\hline $\begin{array}{l}\text { Lyman Alpha Photometer (LAP) Estimation of D-L } \alpha \\
\text { (@ } 121.53 \mathrm{~nm}) / \mathrm{H}-\mathrm{L} \alpha \text { (@ } 121.56 \mathrm{~nm} \text { ) ratio }\end{array}$ & $\begin{array}{l}\text { Investigation of loss process of water in } \\
\text { Martian atmosphere }\end{array}$ & 1.97 & 8 \\
\hline
\end{tabular}


Camera (MCC) images and have been studied for their optical properties. Valles Marineris, a region on Mars comprising of large number of canyon systems on Martian equatorial region, was found to be hazy and covered with dust captured in multiple observations by MCC on October 28, December 5, and December 13, 2014. One of the MCC image over Valles Marineris, which is a large canyon is shown in Fig. 1. The repeated imaging was utilized to study this thick bright haze and to estimate atmospheric optical depth (AOD) using stereo observations (Mishra et al., 2016). Similar dust storms were also observed over the north-west side of Sharonov Crater and Lunae Planum during October 20-28, 2014, a period of mid-southern spring Martian season (Singh and Mishra, 2016). This dust storm was of nearly 2.5-3.5 km height, spread over an area of about 105 $\mathrm{km}^{2}$, indicating that the dust storm was local in extent. Apparent reflectance derived using the Methane Sensor for Mars (MSM) confirmed the presence of dust particles based on their typical reflectance values.

The magnitude and spatial distribution of Martian surface albedo are important parameters for characterization of Martian surface and atmospheric circulation. Global Short Wave Infra-Red (SWIR) albedo map in wavelength band 1.64-1.66 $\mu$ m has been derived using five months (October 2014- February 2015) of MSM radiance data for the surface of Mars (Fig. 2). The global view of MSM derived Martian SWIR albedo has been averaged at $\sim 50 \mathrm{~km}$ spatial resolution. The bright regions (albedo $>0.4$ ) are mainly localized over the Tharsis plateau, Arabia Terra and

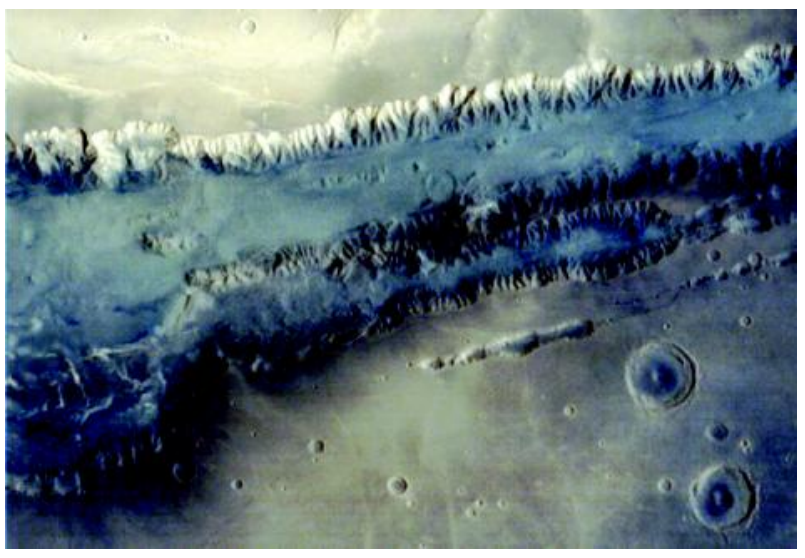

Fig. 1: Image of the central portion of Valles Marineris of Mars taken by Mars Colour Camera on 28-01-2015 at a spatial resolution of $300 \mathrm{~m}$ from an altitude of 5797 $\mathrm{km}$. Wall of the canyon are clearly seen in this image

Elysium Planitia regions of Mars. The low albedo regions $(<0.15)$ are mainly localized in Syrtis Major and Southern highlands and parts of Northern hemisphere. In general, low albedo values are associated with darker surface on Mars having volcanic basalt rocks as surface exposures. Higher albedo values represent surface covered by dust. The area shown in blue color indicates the presence of basaltic composition while red indicates the dust covered regions of Mars.

Another interesting result from MOM mission includes low-latitude Martian neutral exosphere during the evening hours (near Sunset on Mars) using the MENCA in-situ observations (Bhardwaj et al., 2016).

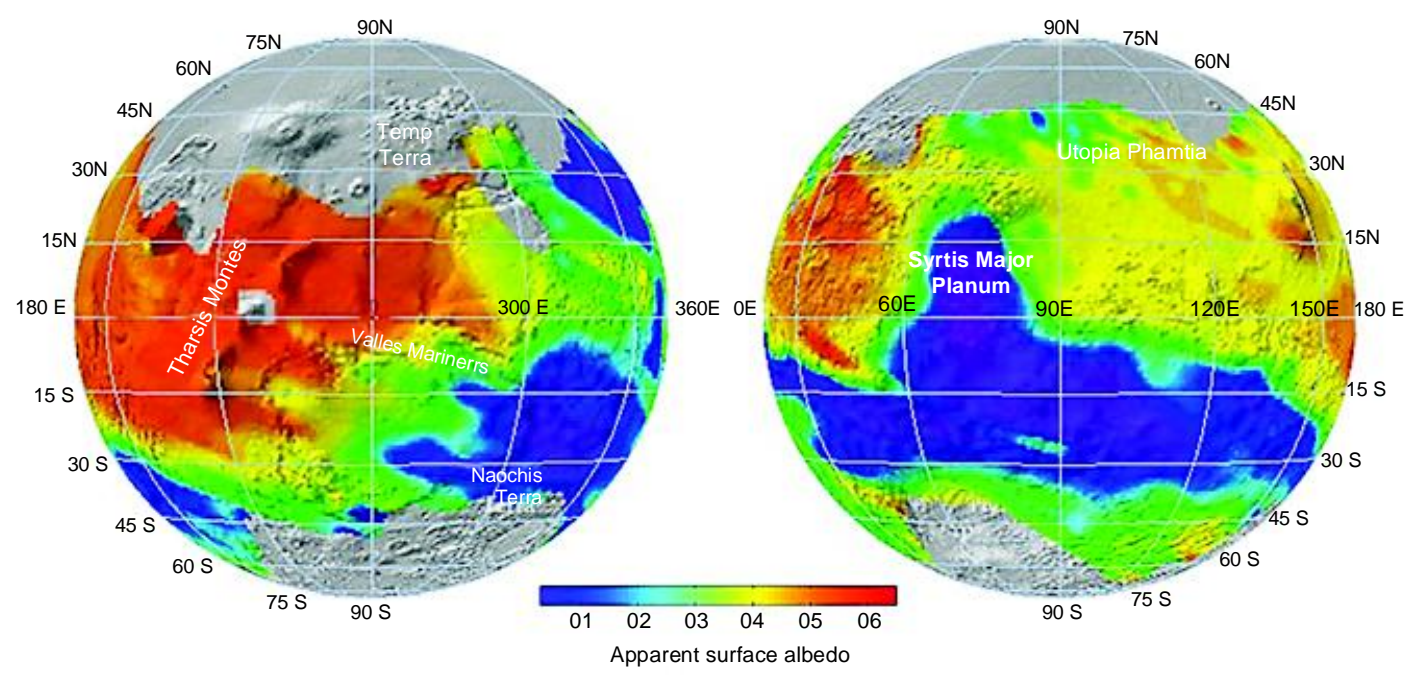

Fig. 2: The Global MSM SWIR $(1.65 \mu \mathrm{m})$ band albedo map of Mars using MSM data 
The altitude profiles from 265 to $400 \mathrm{~km}$ of the major constituents of Martian exosphere, i.e., amu $44\left(\mathrm{CO}_{2}\right)$, amu $28\left(\mathrm{~N}_{2}+\mathrm{CO}\right)$, and amu $16(\mathrm{O})$, during the moderate solar activity conditions and near the perihelion have shown that the abundance of $\mathrm{O}$ exceeds that of $\mathrm{CO}_{2}$ at an altitude of $\sim 270 \pm 10 \mathrm{~km}$ during Martian evenings. From the variation of the abundances of different gases with altitude, the temperature of the Martian exosphere was derived (Fig. 3) and found to be about $270 \pm 5 \mathrm{~K}$ (Bhardwaj et $a l .$, 2016). The Martian evening exosphere shows the most dramatic variations as shown by the MENCA observation and is extremely useful to understand the thermal escape processes.

\section{Imaging of Phobos and Deimos}

The unique elliptical orbit of MOM mission provides rare opportunities to view the two moons of Mars Phobos and Deimos. Deimos is tidally locked with Mars, so the far-side was not imaged by any of the current functional satellites orbiting Mars. Mars Color Camera (MCC), onboard MOM imaged the far-side of Deimos which has not been viewed for the last few decades by any Mars orbiter (Fig. 4) (Arya et $a l .$, 2015b). Four image-frames of the Deimos was acquired on October 14, 2014 at around 13:05 UT which are used to generate a High Dynamic Range (HDR) product so as to enhance the image details. The apparent magnitude, which is defined as the logarithmic luminosity ratio of a body to a standard, is computed using the total count of Deimos (far-side) from MCC image and is found to be about 14.06. The known apparent magnitude of Deimos is about 12.45 (JPL, 2015). The difference could be possibly due to the variation in the near and far side surface

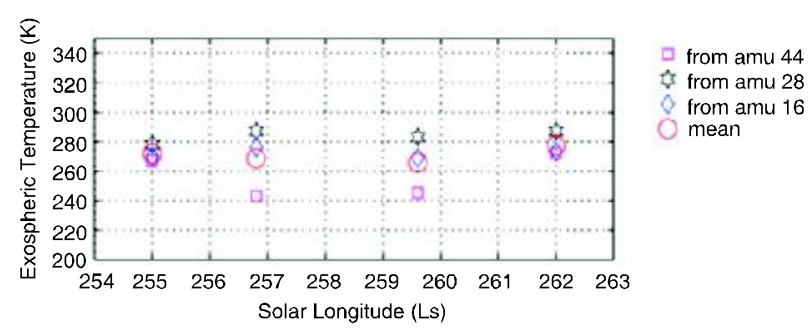

Fig. 3: The variation of evening time ( 17-18.5 Local Solar Time on Mars) exospheric temperature derived from the three major constituents (amu 44, 28, and 16) observed by MENCA-MOM along with their mean temperatures for the four days of observations on 18 , 21, 26, and 29 December 2014 ( $L s=255$-262 degree). (Bhardwaj et al., 2016)

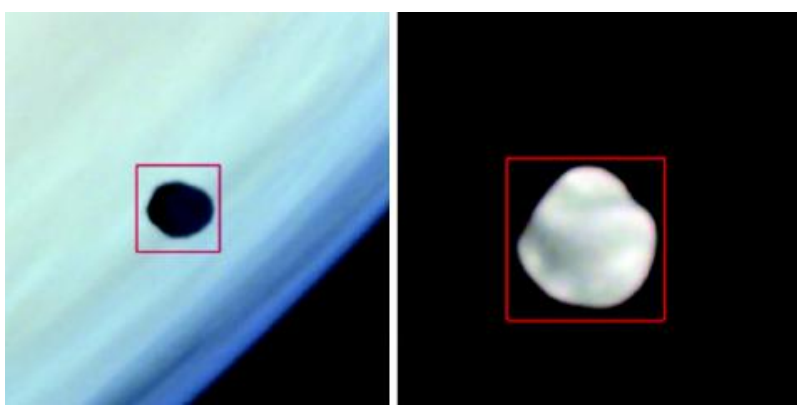

Fig. 4: Phobos and Deimos as seen by MCC on 14th October, 2014

characteristics, or due to different methodology or error thresholds used by different researchers.

\section{Surface Composition of Mars and terrestrial analogues}

Compositional studies provide a wealth of information on the geological conditions prevailing during the evolution of a planet. The compositional information could be extracted from remote sensing data using techniques like reflectance spectroscopy, gamma-ray spectroscopy, X-ray fluorescence. Reflectance spectroscopy. These techniques provide direct information about the surface mineralogy and is widely used to determine the composition of planetary objects. Compositional studies of Martian landforms have been mainly done using hyperspectral data from Mars Reconnaissance Orbiter-Compact Reconnaissance Imaging Spectrometer for Mars (MRO-CRISM). Identification of aqueous minerals on the Martian surface are extremely significant in establishing the presence of water on Martian surface in the past. To understand the same, many studies have been done to identify various aqueous minerals from different geological terrains based on their spectral characteristics (Jain and Chauhan, 2015a,b; Jain et al., 2014). Deposits of serpentine $\left(\mathrm{Mg}_{6}\left(\mathrm{Si}_{4} \mathrm{O}_{10}\right)\right.$ $\left.(\mathrm{OH})_{8}\right)$ and pyroxene have been identified in ArsiaChasma based on the spectral features at 2.32 $\mu \mathrm{m}$ due to $\mathrm{Mg}-\mathrm{OH}$ in serpentine along with $1.94 \mu \mathrm{m}$ due to $\mathrm{H}_{2} \mathrm{O}$ (Jain et al., 2014). Similar mineralogical analysis of Capri Chasma region (Fig. 5) within Valles Marineris confirms the presence of phyllosilicates and carbonates which suggest water activity in the area (Jain and Chauhan, 2015a). The northern region of Hellas Planitia is also found to host phyllosilicate bearing deposits mainly vermiculite (Jain and Chauhan, 

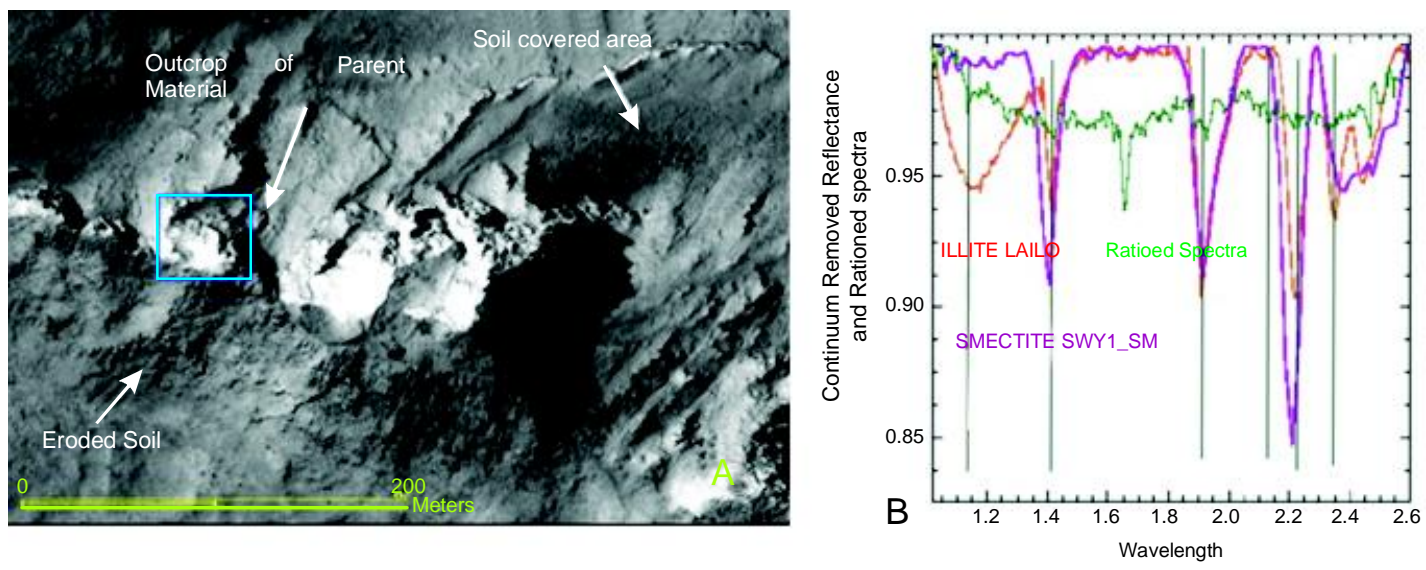

Fig. 5: (A) HiRISE image of portion of Capri Chasma region showing outcrops of Illite clay mineral, (B) rationed spectra of illite (CRISM data) from the study area (green) and spectral signature of ILLITE LAIL02 (orange) (Jain and Chauhan, 2015a)

2015b). Studies using high resolution images of these areas also have been carried out to find morphological evidences like mud cracks, erosional gullies supporting the presence of water in the past (Jain and Chauhan, 2015a).

The similarity of Mars with our planet Earth is very well known and thus, terrestrial landforms, rock/ mineral assemblages provides an excellent analogue to understand Mars in various aspects, especially geological processes. Spectroscopic studies of terrestrial analogues using ASD spectrometer have been done in several parts of India, like Dungarpur, Rajasthan and Kutch, Gujarat to understand the formation of hydrous magnesium mineral serpentine that occur in ultramafic rock types in the Aravalli Supergroup (Bhattacharya et al., 2012b, 2016). Serpentine mineral has been reported from Nili Fossae region of Mars by MRO-CRISM observations which suggest aqueous alteration through hydrothermal activities. Serpentines, associated with phyllosilicates as obtained from the Rikhabhdev ultramafic suite near Dungarpur, Rajasthan act as a potential analogue for the similar mineralogy observed in the Nili Fossae region on Mars (Jain et al., 2012). Another terrestrial analogue study is of Deccan basalt to understand the weathering of basalts on Mars, reported by Greenberger, et al., (2012).The team studied the weathering profile section near Bidar in the southeastern part of Deccan basalt province and found many similarities to the hydrated mineral occurrences and basalt weathering formations on Mars. In the same province, Lonar crater has also served as an excellent terrestrial analog of small impact craters of Mars. A recent study by Kumar et al. (2014) showed the presence of phyllosilicates both in the ejecta and target interior of Lonar crater and assessed their role in the fragmentation outcome of the impact event by a thorough geological and geophysical characterization of the ejecta blanket.

\section{Morphology of Mars}

Geomorphological analysis of any planetary surface is of paramount importance to unravel the processes that shaped the planetary landscapes. High resolution data acquired from the Martian surface has made it possible to appreciate the beautifully carved surface of Mars by various geological processes especially by liquid water, ice/snow and wind. Such an attempt has been made to understand the geomorphology of Martian surface using data from Mars Reconnaissance Orbiter (MRO) High Resolution Imaging Science Experiment (HiRISE) images at $0.25 \mathrm{~m} / \mathrm{pixel}$, ConText Camera (CTX) images at $6 \mathrm{~m} /$ pixel and Mars Global Surveyor (MGS) Mars Orbiter Camera (MOC) narrow-angle camera (NAC) images $(1.5-12 \mathrm{~m} /$ pixel). An exemplary study is by Sinha and Murty (2013a), in which the distribution, orientation, and geology/geomorphology of 30 craters lying within the Alba Patera volcanic province has been studied in details for the glacial/periglacial features. It is revealed that the glacial/periglacial features in Alba Patera are mainly present within pole-facing slopes of craters lying within $45^{\circ} \mathrm{N}-39^{\circ} \mathrm{N}$. The study further concluded the period of ice/snow accumulation activity 
in Alba Patera occurred throughout the Amazonian and lasted until the recent past, i.e., 2.1-0.4 Ma. Researchers have also identified multiple episodes of glacial activities in Deuteronilus Mensae region on Mars (Fig. 6) similar to the glacial landforms as in Himalaya, Antarctica, and parts of Alaska on Earth (Sinha and Murty, 2013b). Another study to understand the glaciation on Mars includes an in-depth investigation of Moreux crater for identification of features associated with recent and episodic glacial events (Sinha and Murthy, 2015). Many evidences for extensive modification of the surfaces by emplacement of multiple scales of ice-rich landforms were found. These changes are representative of a long history of glacial activities that has occurred over the last tens of millions of years on Mars.

\section{Modeling Studies on Martian Atmospheric Emission}

The first detailed model of $\mathrm{N}_{2}$ Vegard-Kaplan band emissions on Mars to explain the recent SPICAM observations on board the European Mars Express mission has been developed, which suggests that the $\mathrm{N}_{2}$ density in Martian model atmospheres must be reduced by a factor of 3 (Jain and Bhardwaj, 2011). Recently, a detailed assessment about the impact of the two most commonly used solar EUV flux models on photoelectron fluxes, ion densities and COCameron and $\mathrm{CO}_{2}{ }^{+} \mathrm{UV}$ doublet band day glow emissions on Mars in different solar activity conditions has been

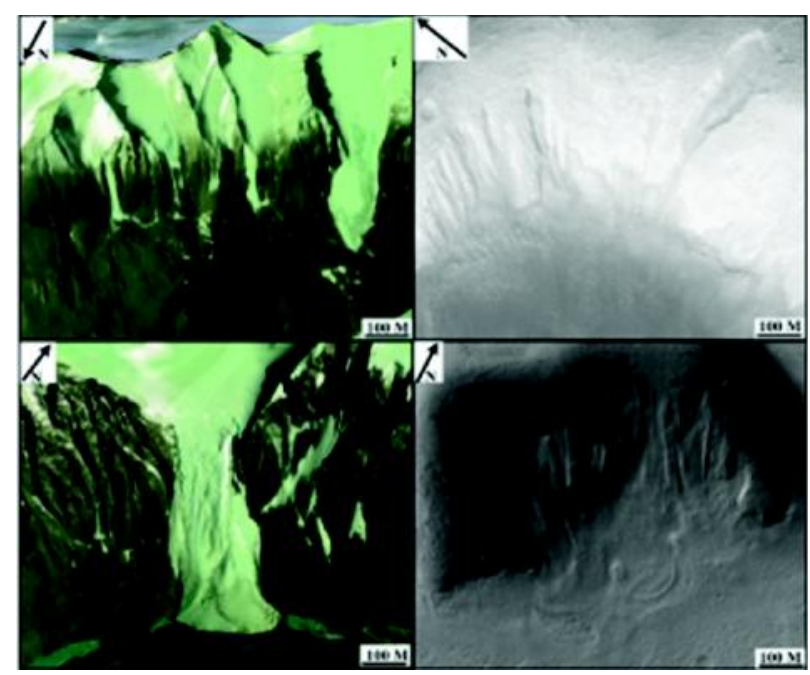

Fig. 6: Example of glacial features within Deuteronilus Mensaeregionon Mars and in the Antarctica on Earth from Google Earth/Mars (Sinha and Murty, 2013b) made which showed that change in solar flux model can alter the emission brightness up to $50 \%$ - a result that has several implications for Martian aeronomy (Jain and Bhardwaj, 2012). More recently, a new model has been developed for calculating atomic oxygen red (6300 ̊̊), green (5577 $\mathrm{A})$ and UV (2972 $\AA$ ) line emissions in the sunlit atmosphere of Mars. The model predicted that the OI green line is more intense than the red line. Thus, the search for $5577 \AA$ emission in Mars Dayglow should focus at altitudes below $150 \mathrm{~km}$ (Jain and Bhardwaj, 2013).

\section{Geochemical Evolution of Mars}

Meteorites originating in Mars give valuable and precise information about Martian processes occurring at the time the meteorite was ejected from Mars since they can be subjected to detailed analysis with sophisticated instruments in the laboratory. Recently a new unaltered piece of Martian volcanic material, known as Tissint meteorite (Fig. 7), provided new stringent information on petrogenesis of the Martian rocks (Basu Sarbadhikari, 2015; Basu Sarbadhikari et al., 2016). Tissint retains a unique characteristic of impact-induced melting and deformation, forming phosphorus-rich re-crystallization rims of olivine and shock-induced melt domains without relative enrichment of LREEs compared to the bulk. Mineral chemical composition of Tissint can be compared to the enriched and depleted groups of basaltic shergottites. For example, high modal concentration of high-Ca pyroxene with respect to plagioclase in Tissint is comparable to the enriched basaltic shergottites than the depleted shergottites. Bulk major element composition and therefore $P-T$ phase saturation during early to intermediate stage of crystallization resemble more closely to the enriched shergottites while late-stage rapid crystallization is more alike the depleted shergottites, indicating different petrogenesis of Tissint with respect to other depleted shergottites. This study questions uniformity and homogeneity of the depleted mantle source of shergottites, as the depleted shergottites are all believed to have been ejected from a particular locale by virtue of a single impact event. The enrichment of $\mathrm{Al}, \mathrm{Ca}, \mathrm{Na}, \mathrm{P}$ and REE contents in the whole-rock of Tissint may indicate the effect of crustal assimilation or magma mixing processes during the late-stages of crystallization of primary Mg-rich phases. Model calculation indicates that $0.1-2 \%$ mixing of the 


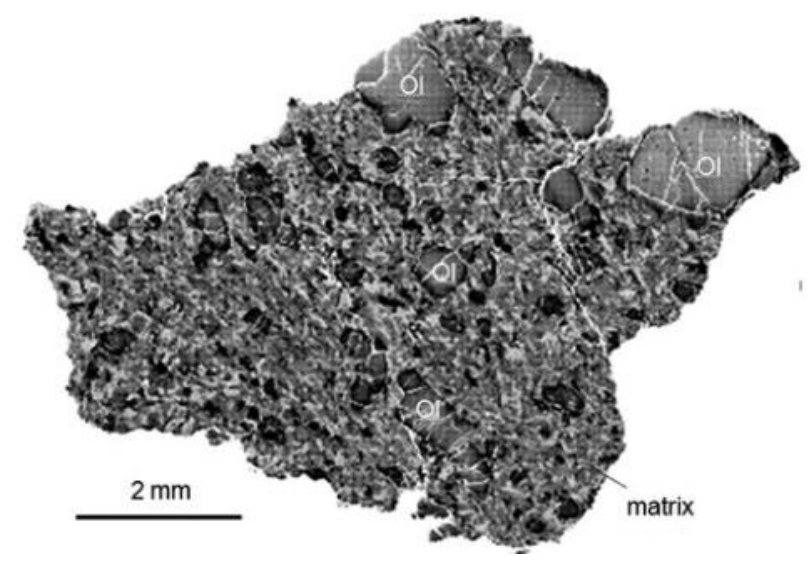

Fig. 7: Inverse gray-scale Back Scattered Electron (BSE) image of one whole-section of Tissint. Some of the olivine (Ol) magacrysts are marked

enriched crustal and trapped melt components were required to reproduce the evolved melt composition and the whole rock of Tissint. This model calculation explains that the enrichment did reset the whole-rock trace-element budget in Tissint. This study indicates the presence of $\mathrm{Al}, \mathrm{Ca}, \mathrm{Na}, \mathrm{P}$ and REE- rich layer at the shallower upper mantle above the depleted mantle source region during the geologic evolution of Mars. The existence of both the depleted and enriched mantle source regions in the upper mantle of Mars, of different source craters, has global implications to the inherent heterogeneity of the mantle sources of the shergottites. The depleted as well as the enriched mantle sources of shergottites were chemically layered through their evolution in geologic time. Martian meteorite Tissint therefore records unique petrogenesis process in the upper mantle of Mars.

\section{Lunar Exploration}

Chandrayaan-1, the Lunar polar orbiter mission of Indian Space Research Organization (ISRO) successfully imaged lunar surface during 2008-2009 (Goswami and Annadurai, 2009). A large number of studies have been done using the data collected by this mission. Summary of the results from Chandrayaan-1 data published can be found in Chauhan et al., 2012, 2015, Bhandari and Srivastava, 2014, and Bhardwaj et al. (2015b). Recent studies from Chandrayaan-1 data revealed some remarkable findings which are discussed in this paper. A significant conceptual change about the Moon is that it is not dry, passive and inactive as was once thought to be, but has a dynamic, though tenuous, hydrosphere, is tectonically active and there is evidence of recent (2$10 \mathrm{Ma}$ ) volcanic activity (Bhandari and Srivastava, 2014).

\section{Detection of $\mathrm{OH} / \mathrm{H}_{2} \mathrm{O}$ Hydration Feature}

Detection of water on the lunar surface has always been a subject of prime interest in lunar exploration. Remote detection of hydration $\left(\mathrm{OH} / \mathrm{H}_{2} \mathrm{O}\right)$ features on the lunar surface by Chandrayaan-1 mission has sparked much interest in the science community to look back to Moon in completely new perspective (Clark, 2009; Pieters et al., 2009; Sunshine et al., 2009). Water and water-ice detected from the permanently shadowed regions (PSRs) of lunar poles using SAR data (Spudis et al., 2010) have been confirmed by the in-situ measurements by LCROSS impact experiment (Colaprete et al., 2010). Hydroxylbearing exposures of possible magmatic origin have been recently reported from the spinel-rich central peak of crater Theophilus and silicic lithology (Bhattacharya et al., 2013, 2015a,b) which strongly suggest the existence of a hydrous lunar mantle. Similar hydrated lithology has been reported from the Jackson crater (Fig. 8) (Chauhan et al., 2014), Lowell crater (Srivastava et al., 2013) and from various other regions in association with olivine, possibly of mantle origin (Bhattacharya et al., 2015b). These new findings on surface and internal or magmatic water on Moon has completely changed our understanding about the key question of water on Moon.

\section{Tectonics on the Moon}

Tectonics and seismicity of lunar surface is another intriguing area which is yet to be properly understood. Structural and tectonic features like faults and scraps present over the lunar surface have been identified which provide insight into the lunar crustal stresses and tectonism. 'Lobate scarps' represents such compressional features and are indicative of recent young age tectonics on the Moon. Efforts have been made using high resolution images along with MiniSynthetic Aperture Radar (Mini-SAR) data by various researchers to identify such features which are indicative of recent crustal tectonics, such as fault lines, thrust fault scarps, and dislocation of debris along the identified fault planes. The ability of radar to penetrate the surface layer along with certain decomposition techniques can reveal some obscure unique features indicative of hidden tectonics which 


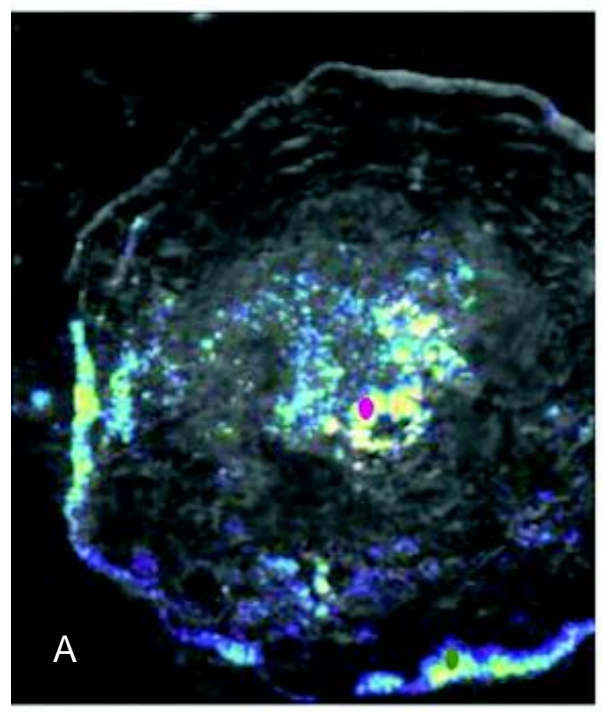

A

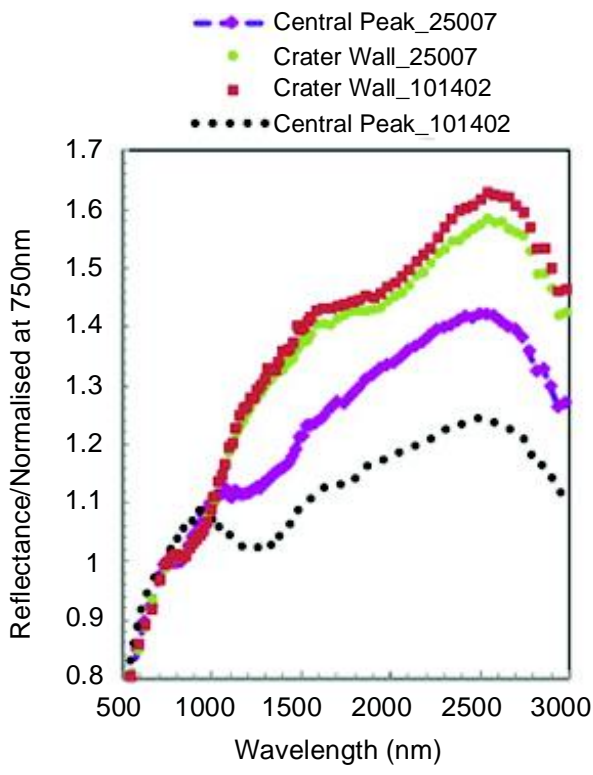

B

Fig. 8: (A) Band depth image of $\mathrm{OH} / \mathrm{H}_{2} \mathrm{O}$ generated from M3G20090621T025007 where red color signifies maximum signal. The high strength has been observed from the central peak as well on the crater wall and (B) reflectance spectra showing $2.8 \mu \mathrm{m}$ absorption characteristic of $\mathrm{OH} / \mathrm{H}_{2} \mathrm{O}$

are otherwise not visible in optical images. The $m-\chi$ decomposition is widely used to locate hidden lineaments and lobate scarps present within shadowed crater floors as well as over the illuminated regions of the lunar surface. South Polar Region of the Moon was explored using Mini SAR data and Lunar Reconnaissance Orbiter Camera (LROC) images for identification of tectonic features (Mukherjee and Singh, 2015).

Another recent significant study of young lobate scarps associated with shallow moonquakes in the Schrödinger basin has been recently published by Kumar et al. (2016). In this study, LROC and Chandrayaan-1 Terrain Mapping Camera (TMC) images were used which revealed four lobate scarps in different parts of the Schrödinger basin. Crater size frequency distribution (CSFD) technique suggests very young age for the scarps of $\sim 11$ to $35-82 \mathrm{Ma}$. Boulder falls recognized with the scarps indicated a recent seismic activity along the scarps. A low runout efficiency of the boulders $(\sim 2.5)$ indicated low to moderate levels of ground shaking, which the authors interpreted to be related to low-magnitude moonquakes in the scarp. It is concluded from this study that a combination of recent shallow moonquakes and impact events triggered the boulder falls in the Schrödinger basin.

\section{Impact spallation processeson the Moon}

Impact spallation is a fundamental process responsible for formation of ejecta boulders from impact craters on planetary surfaces. Although theoretical spallation models were developed about three decades ago, only limited geological observations have so far been made to test these models. In order to provide more observational insights to this aspect, Krishna and Kumar (2016) studied a $3.8 \mathrm{~km}$ Censorinus Crater on the Moon (Fig. 9). Using the Lunar Reconnaissance Orbiter camera images, the authors presented ejecta boulder distribution map of the crater and measurements of sizes and shapes of the boulders, by mapping of more than 240000 ejecta boulders. They documented the size distribution of boulders, both radial and concentric to the impact crater. The boulder distribution pattern exhibited a radial asymmetry with reference to impact direction. The cumulative sizefrequency distribution (CSFD) of boulders registered highly variable fragmentation history in which the uprange boulders suffered more complex fragmentation. The authors also presented theoretical spallation models for the crater, which show subtle differences when compared to the boulder observations, implying the roles of complex fragmentation processes, which have not yet been accounted by the theoretical models. 


\section{Study of Silicic Volcanic Domes}

Volcanic calderas on the Moon are rare, unique volcanic structures that represent extrusive silicic volcanism on the lunar surface. Compton-Belkovich Volcanic Complex (CBVC) $\left(60.5^{\circ} \mathrm{N}-99.5^{\circ} \mathrm{E}\right)$ is an example of extrusive silicic volcanism and is characterized by high-Thorium anomaly. Study of these silicic domes from high-resolution hyperspectral and panchromatic images provided much new and interesting information regarding the formation, evolution and mineralogy of silicic bodies on the Moon. Use of hyperspectral data spectral data lead to identification of spinel mineral from a similar dome namely, Hansteen Alpha which is reported for the first time from a silicic lithology on the Moon (Kaur et al., 2013a). Endogenic magmatic water signature has also been reported from these two domes (Bhattacharya et al., 2013). The Compton-Belkovich volcanic complex has been studied in detail by Chauhan et al. (2015) for its various morphological and structural features using LROC NAC and Mini-RF data and they mapped several structural features such as ring faults, radial faults, and fractures (Fig. 10). These structures are manifested by various morphological structures such as domes of varied sizes and shapes and pyroclastic ash flows which characterize it to be a volcanic caldera. Using radar data, it is concluded that the CBVC is basically a localized ash flow caldera characterized by combination of dome complexes, caldera bounding faults and ash flows, all the features being consistent with evolved silicic magmatism in the area (Chauhan et al., 2015).

\section{Utilization of Radar Data for Studying Lunar Surface}

Radar data have been widely used not only to search for the ice/water-ice deposits in permanently shadowed regions but also for mapping of sub-surface structural features, detection of buried melt deposits and ejecta patterns, study of pyroclastic deposits and many other features. The high-resolution, S-band (13 $\mathrm{cm})$ compact polarimetric (CP) SAR data from the Mini-RF aboard LRO have also been used for estimating thermal dielectric permittivity of the lunar regolith (Bhattacharya et al., 2015). Interaction of radar waves with lunar regolith can provide numerous important information, which can be used to decipher regolith thickness distribution. Studies have been done to estimate the regolith thickness using simulated passive microwave brightness temperature (TB) expected from upcoming Chandrayaan-2 mission at $\mathrm{L}(1.25 \mathrm{GHz}$ )- and $\mathrm{S}(2.1 \mathrm{GHz}$ )-bands (Vijayan et al. 2015). Bulk density $(\rho)$, dielectric permittivity and $\mathrm{FeO}+\mathrm{TiO}_{2}(\mathrm{~S})$ content were used as varying parameters to simulate TB from a three-layermodel to estimate the thickness. This proposed study has important implications for estimating the regolith thickness using the MiniSAR frequencies at L- and S-band of the Chandrayaan-2 mission.

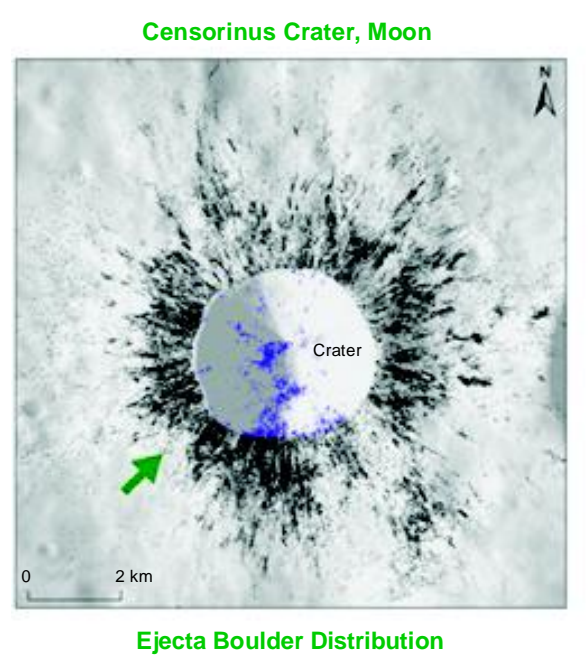

A

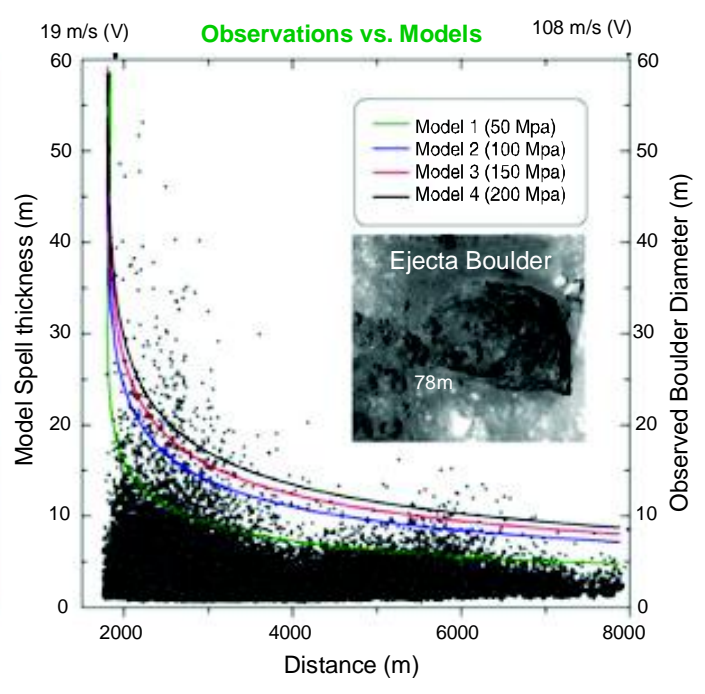

B

Fig. 9: (A) Censorinus Crater showing the distribution of ejecta boulders (black dots) and the boulders on the crater interior (blue dots) and (B) the theoretical spallation model of Melosh (1984) applied to Censorinus Crater 

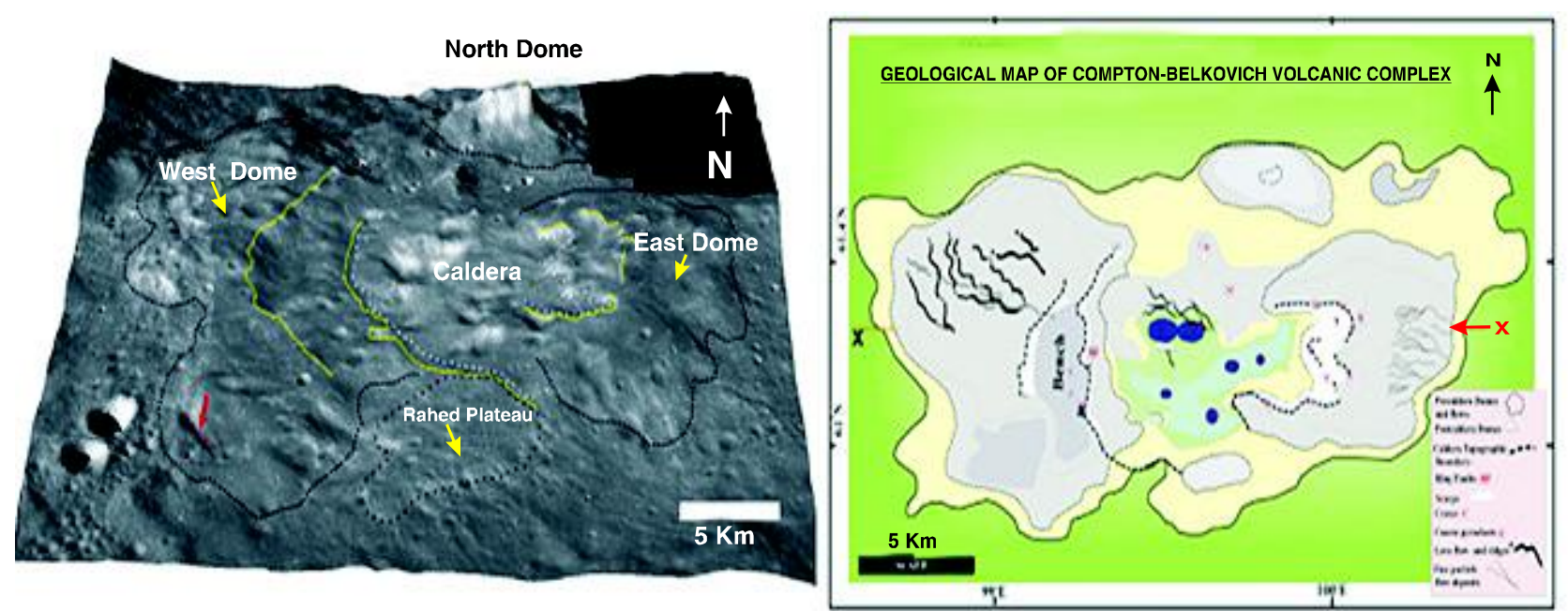

Fig. 10: 3-D surface view and geological map of Compton-Belkovich volcanic complex

\section{Young Volcanism and Impact Cratering on Lunar Surface}

Impact cratering and volcanism are the second most important geological process that have largely sculptured the lunar surface. The lunar surface is characterized by asymmetric distribution of its volcanic deposits. Young volcanic activities and young melt flows associated with impact craters are debatable since the volcanism on the Moon is thought to have been ceased $\sim 1$ billion years ago. However, recent high resolution data have discovered revealing details about the current magmatic history of the Moon through identification of fresh thrust faults and some fresh resurfacing events on the lunar surface. Srivastava et al. (2013), Gupta et al. (2014) and Srivastava and Varatharajan (2016) have reported a distinct freshly produced resurfacing flow covering an area of $\sim 60 \mathrm{sq} \mathrm{km}$ on the far-side Lowellcrater of the Orientale basin (Fig. 11). The analysis was done using high resolution data from recent lunar missions i.e. Chandrayaan-1, LRO and Kaguya, which have shown confinement of this unique resurfaced unit to a possible graben-like structure along alineament in the Copernican aged Lowell crater. The resurfacing unit occupies an area of $\sim 64 \mathrm{~km}^{2}$ with an estimated volume of $\sim 0.96 \mathrm{~km}^{3}$. Various considerations involving geologic context, topographic relations, morphology and spectral composition have suggested that the unit formed due to recent basaltic volcanism in the area. Extreme scarcity of superposed impact craters on the surface suggests a very young age of $\sim 2-10 \mathrm{Ma}$ for this volcanic formation, making it the youngest volcanic activity reported on the Moon.

Srivastava and Varatharajan (2016) further revealed that the Lowell crater formed $374 \pm 28 \mathrm{Ma}$ ago due to an oblique impact of a $\sim 5.7 \mathrm{~km}$ diameter bolide from the S-SW direction, at an angle of 30-45 degrees suggesting that that the Moon was hit by at least four $\sim 6 \mathrm{~km}$ diameter projectiles during the Younger Copernican period; the other 3 resulted in formation of craters Jackson, Ohm and Tycho. Morphological characteristics of the Lowell crater suggest that undifferentiated mantle of the Moon could be exposed in its central peak.

In another study, Sruthi and Kumar (2014) analyzed Lunar Reconnaissance Orbiter (LRO) and Chandrayaan-1 Moon Mineralogy Mapper $\left(\mathrm{M}^{3}\right)$ data of $143 \mathrm{~km}$ Antoniadi impact basin and presented a new geological map of the basin. Distribution of secondary craters around Antoniadi showed that it was an oblique impact event with a trajectory of $50^{\circ}$ counter-clockwise from $178^{\circ} \mathrm{E}$ longitude. The geological mapping led to new findings of several volcanic cones (0.2-2.5 km diameter) in association with the mare basalt flows. The CSFD of the mare deposits suggested a range of ages, varying from 1.6 Ga to $2.6 \mathrm{Ga}$, possibly indicating the episodic volcanism in the basin. The young volcanism of $1.6 \mathrm{Ga}$ was reported for the first time from SPA. The $\mathrm{M}^{3}$ data revealed that the basin materials contained abundant low-Ca pyroxene, while the mare basalts had highCa pyroxene. 

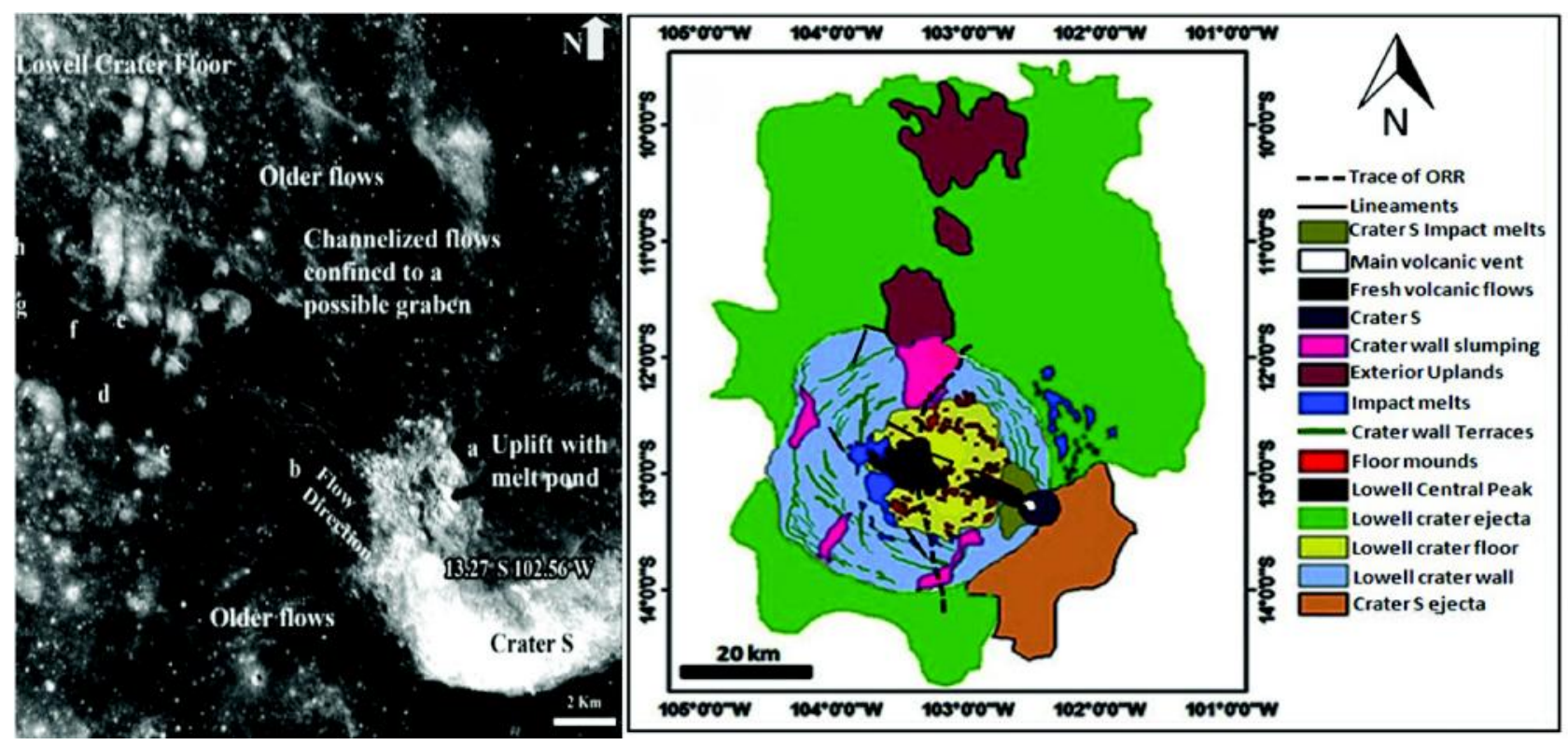

Fig. 11: (A) Morphogical details of a part of the resurfaced area of Lowell crater (Srivastava et al., 2013) and (B) geological map of the Lowell crater (Srivastava and Varatharajan, 2016)

A comparative assessment of the mineralogy of young basalts $(\sim 1.2 \mathrm{Ga}$ to $\sim 2.8 \mathrm{Ga})$ from the western nearside, Moscoviense basin, Orientale basin and Oceanus Procellarum region has been made using Moon Mineralogy Mapper $\left(\mathrm{M}^{3}\right)$ data from the Chandrayaan-1 mission by Varatharajan et al., 2014. The study revealed that, mineralogy of the mare basalts which erupted during the late stage volcanism vary across the Moon's surface. The broader observations reveal apparently higher $\mathrm{FeO}$ content in the younger basalts of western nearside and Orientale region.

\section{Gullies and Landslides on the Moon}

Kumar et al. (2013) observed gullies and erosional landforms on the Moon and attributed them to drygranular flows. In their study, high-resolution images from Chandrayaan-1 Terrain Mapping Camera and Lunar Reconnaissance Orbiter Camera revealed landslides and gully formation on the interior wall of a $7 \mathrm{~km}$-diameter simple crater emplaced in the Schrödinger basin on the farside of the Moon. The counting of fresh impact craters on the interior wall of host crater suggested a minimum age of $18-2 \mathrm{Ma}$ for the gullies and $2 \mathrm{Ma}$ for the landslides, while age of the host crater ejecta was found to be $\sim 175 \mathrm{Ma}$.

\section{Atmosphere of Moon as Observed by CHACE Aboard MIP/Chandrayaan-1}

The Chandra's Altitudinal Composition Explorer (CHACE) instrument was part of the Moon Impact Probe (MIP) onboard Chandrayaan-1. The MIP was detached from Chandrayaan-1 orbiter at $100 \mathrm{~km}$ altitude and impacted near the South pole at $89^{\circ} \mathrm{S}$ on 14 November 2008 (Sridharan et al., 2010). CHACE instrument is a quadrupole mass spectrometer with unit mass resolution and 1-100 amu mass range. CHACE observations enabled study of the relative concentration of the isotopes of ${ }^{40} \mathrm{Ar}$ and ${ }^{36} \mathrm{Ar}$ along the $14^{\circ}$ E lunar meridian (Sridharan et al., 2013). The ${ }^{40} \mathrm{Ar}$ is known to be a product of the radioactive decay of ${ }^{40} \mathrm{~K}$ from the Moon's interior, while lunar ${ }^{36} \mathrm{Ar}$ is primordial having solar wind origin. $\mathrm{The}{ }^{40} \mathrm{Ar}:{ }^{36} \mathrm{Ar}$ ratio is less than $5 \times 10^{-4}$ in the solar wind and any significantly higher value of this ratio indicates the presence of radiogenic ${ }^{40} \mathrm{Ar}$. The observations from CHACE have yielded clues on the possible spatial heterogeneity in the radiogenic activity of the lunar interior. The $\mathrm{Ar}^{40}: \mathrm{Ar}^{36} \mathrm{Ar}$ ratio of $\sim 1$ is observed in the Moon's Northern hemisphere and 2.5 in the southern hemisphere. CHACE observations are used to generate 2-D (latitude versus altitude; Fig. 12) maps of the lunar ${ }^{40} \mathrm{Ar}, \mathrm{H}_{2}$ (Smitha et al., 2015). Lunar Ar is observed to be maximum in the lower and mid- 

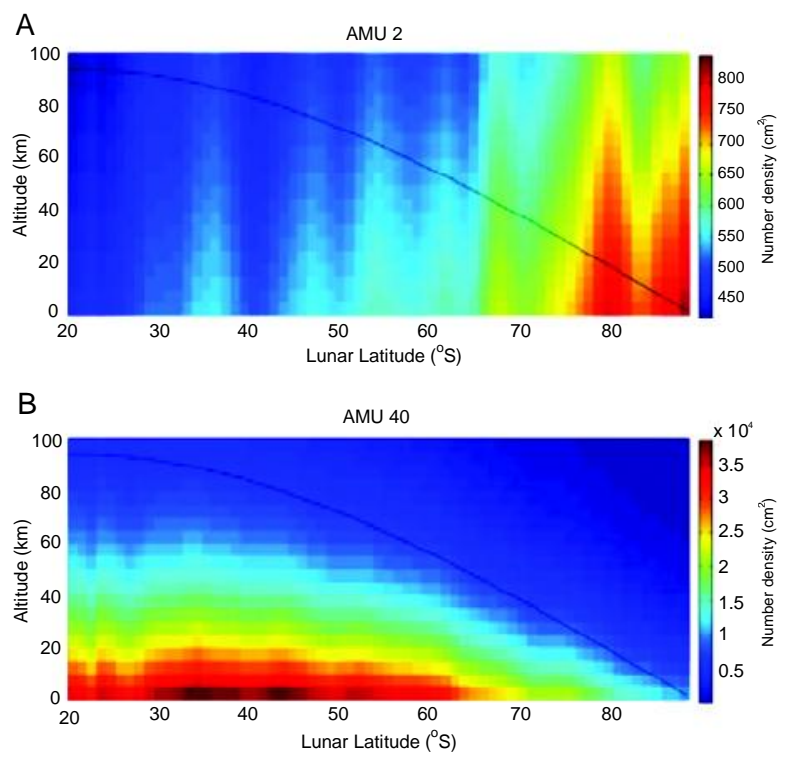

Fig. 12: 2-D maps of $\mathrm{H}_{2}$ and ${ }^{40} \mathrm{Ar}$ generated from the CHACE observations. The black line represents the trajectory of the MIP (Smitha et al., 2015)

latitudes and less in the higher and polar latitudes because of the condensation losses. $\mathrm{Ne}$ and $\mathrm{H}_{2}$, on the other hand, being non-condensable at the lunar temperature and pressure conditions, maximise at the higher, polar latitudes. The latitudinal and altitudinal distribution of Neon in the sunlit lunar exosphere measured by CHACE (Fig. 13) is found to vary from $(7-22) \times 10^{3} \mathrm{~cm}^{-3}$ at the pole, to $(3-5) \times 10^{3} \mathrm{~cm}^{-3}$ in mid $\left(50^{\circ} \mathrm{S}\right)$ latitudes and to $(0.5-1.1) \times 10^{3} \mathrm{~cm}^{-3}$ in lower $\left(20^{\circ} \mathrm{S}\right)$ latitudes (Das et al., 2016). The CHACE results highlight the complexities of the lunar atmosphere and the significant role of the lunar surface

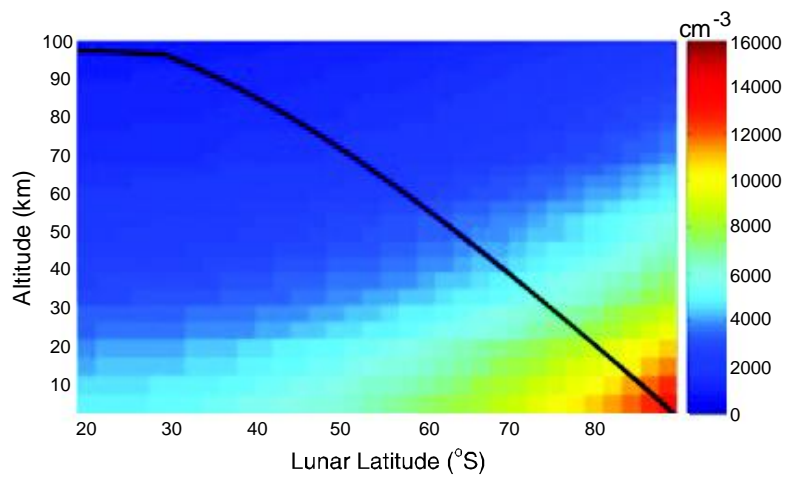

Fig. 13: 2-D map of Neon in the sunlit lunar exosphere generated from the CHACE observations. The black line represents the trajectory of the MIP (Das et al., 2016) processes in modulating the distribution of the different species in the lunar exosphere.

\section{Interaction of Solar Wind with the Moon's Surface}

The observations by the CENA sensor of the SARA experiment onboard Chandrayaan-1 (Bhardwaj et al., 2010; Barabash et al., 2009) provided new insights into the energetic neutral atom (ENA) environment around the Moon.The estimated backscatter fraction (albedo) of hydrogen ENAs from Chandrayaan-1 observations is about $8-28 \%$. These values are much higher than those expected prior to SARAChandrayaan-1 observations. The ENA intensity displayed variations with the solar zenith angle. The derived angular scattering function for the ENAs using CENA observations (Schaufelberger et al., 2011) suggests more scattering in the sunward direction (backscattering) than the forward scattering as the

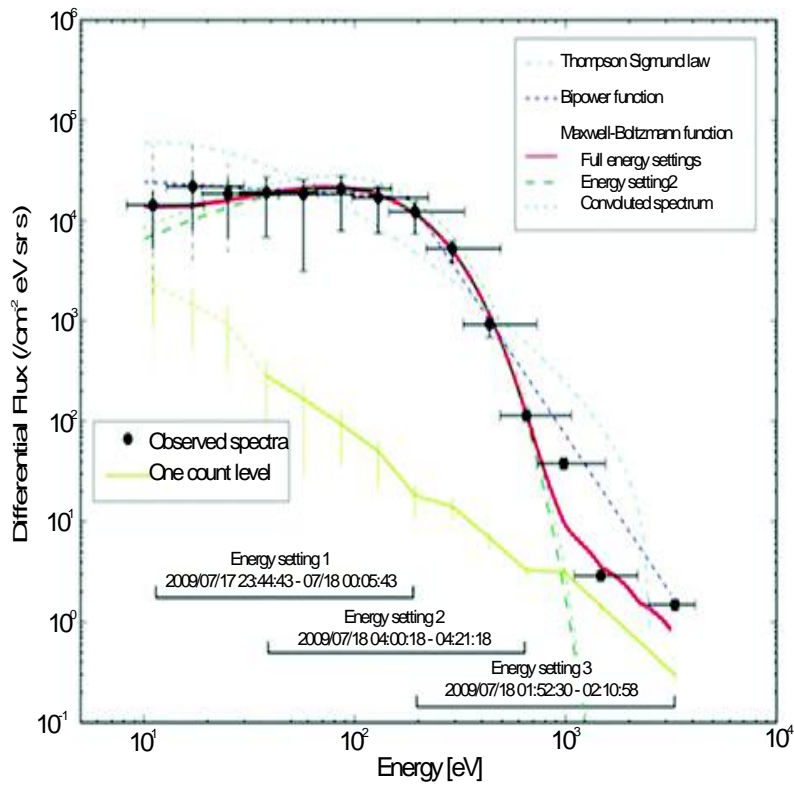

Fig. 14: The energy spectrum of backscattered ENAs observed by SARA/CENA along with the fitted curves. Data are averaged over 3 orbits during 17-18 July 2009. The fits for the Thompson-Sigmund law (light blue line), the bi-power law (blue line), and the Maxwell-Boltzmann distribution (red line) are shown. The green dashed and the green dotted curves show the fits for the Maxwell-Boltzmann distribution only for the data corresponding to the energy setting 2 (38-652 eV) and the MaxwellBoltzmann distribution convolved with relatively wide energy resolution and response functions, respectively (Futaana $e t$ al., 2012) 
solar zenith angle increases, which is contrary to the expectations based on laboratory studies. Using this scattering function, the global mean for hydrogen ENA albedo from CENA/ SARA is found to be $16 \pm 5 \%$ (Vorburger et al., 2013). The energy spectrum of the backscattered hydrogen ENAs is Maxwellian (Fig. 14) and that the ENA characteristic energies are correlated with the solar wind velocity (rather than solar wind energy). This implied that the ENA emission is a momentum-driven process and the impacting solar wind protons experience multiple collisions within the top layer of the regolith before getting released into the space as neutral hydrogen (Futaana et al., 2012).

Since the interaction of solar wind with Earth's magnetic field results in the formation of magnetosphere which effectively shields the planet from the solar wind, the possibility that magnetic anomaly regions on Moon can form small-scale magnetospheres ("mini-magnetospheres") has been suggested from Lunar Prospector observations. The discovery of "mini-magnetosphere" on Moon was made possible by means of ENA observations from Chandrayaan-1 over the Crisium antipode magnetic anomaly region (Wieser et al., 2010). The spatial extent of the mini-magnetosphere was found to be $\sim 360 \mathrm{~km}$ across at the lunar surface. The ENA intensity was found to reduce by about $50 \%$ within the area of the mini-magnetosphere. This region of reduced ENA intensity was surrounded by a region of enhanced ENA intensity of width $\sim 300 \mathrm{~km}$ which is due mini-magnetosphere (Fig. 15).

Using the entire data of ENA observations by Chandrayaan-1/CENA, the first global ENA albedo map covering $\sim 89 \%$ of the lunar surface has been generated (Vorburger et al., 2013) (Fig. 16). Local variations in the ENA albedo were seen from the map, which indicated that lunar surface is not a homogeneous ENA reflector but exhibits local variations and the signatures of the anomaly regions could be clearly seen in the map. The analysis of ENAs from the South pole Aitken basin has been carried out to investigate the effect of the surface properties on the variation of backscattered ENA albedo (Vorburger et al., 2015). South pole Aitken terrain has highly variable surface properties and magnetic anomalies around the rim. The analysis showed that the ENA albedo is sensitive to magnetic anomalies

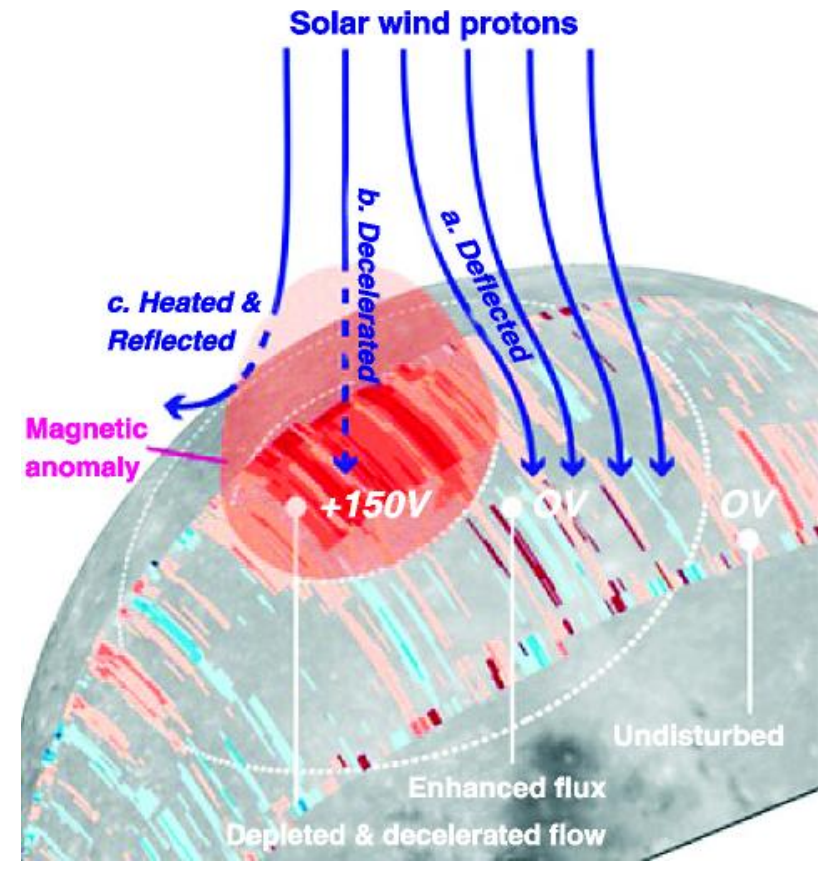

Fig. 15: Illustration of the solar wind interaction with the lunar magnetic anomaly based on SARAChandryaan-1 observations. The blue lines indicate the flow of solar wind protons that are subsequently modified by the interaction with the magnetic anomaly resulting in (A) deflection and thereby reaching the enhanced region without a change in velocity, (B) deceleration inside the magnetic anomaly due to the potential structure of $+150 \mathrm{~V}$ and reach inside magnetic anomaly, or $(C)$ heating and reflection to space before reaching the lunar surface (Futaana et al., 2013)
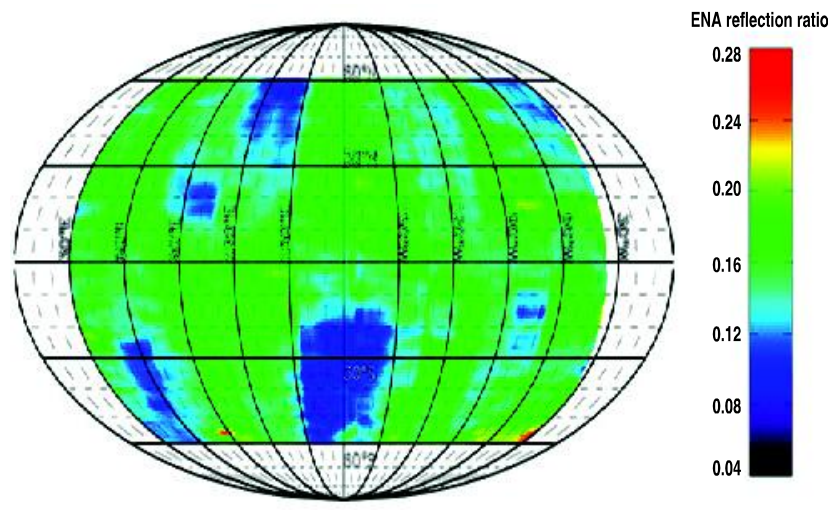

Fig. 16: The map of lunar hydrogen ENAs from the Moon from the SARA observations on Chandrayaan-1 (Vorburger et al., 2013)

which causes the suppression of ENA intensity, whereas the other surface properties, e.g., changes 
in elevation of surface, chemical composition, and visible albedo do not play any significant role in the variation of ENA albedo.

Hydrogen ENAs are also found to be produced when the Moon is in the geomagnetic tail, or in magnetosheath where the plasma conditions are different compared to upstream solarwind (Harada et al. 2014; Lue et al., 2016). The first direct observational evidence for the solar wind sputtering of lunar surface came from CENA/SARA sensor of Chandrayaan-1 with the observation of sputtered oxygen atoms (Vorburger et al., 2014). The sputtered oxygen flux is around 0.2-0.4 times that of the backscattered hydrogen ENA flux. As expected, the sputtered flux was found to be higher when the solar wind had higher $\mathrm{He}^{++}$content, since $\mathrm{He}^{++}$is a more efficient sputtering agent compared to $\mathrm{H}^{+}$due to its higher mass. Due to the high absorption of solar wind plasma on the lunar dayside, a large scale wake structure is formed downstream of the Moon. However, recent in-situ observations have revealed the presence of protons in the near-lunar wake (100$200 \mathrm{~km}$ from the surface). The solar wind, either directly or after interaction with the lunar surface (including magnetic anomalies), is the source of these protons in the near-wake region (Bhardwaj et al., 2015b). Recently, using observations made by SWIM sensor of SARA/Chandrayaan-1, it has been shown that the protons from the tail of the solar wind velocity distribution, that have gyro-radii larger than the radius of the Moon, can directly enter the lunar wake region (Dhanya et al., 2013). Further, from a detailed analysis of the velocity distribution of the protons observed in the near-lunar wake, using the entire data set from the SWIM/SARA experiment onboard Chandrayaan1 (Fig. 17), several proton populations were identified and their possible entry mechanism were inferred, which indicated the control of IMF in the proton entry processes into lunar wake (Dhanya et al., 2016).

Figure 18 summaries the current understanding of the various processes initiated by the interaction of solar wind with the Moon. Such processes include, but are not limited to, backscattering of solar wind protons as hydrogen ENAs, sputtering of the lunar surface, scattering of solar wind protons from the lunar surface as well as from magnetic anomalies, nightside ions, and plasma dynamics in near-lunar wake.

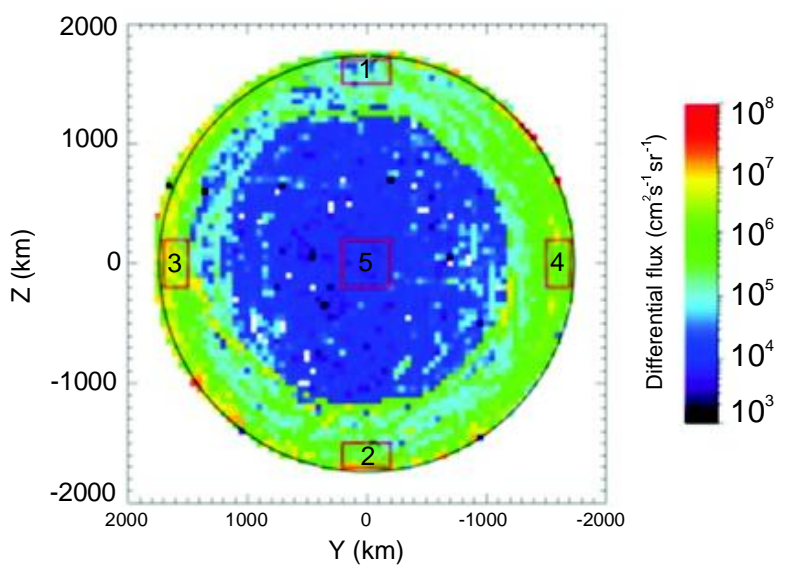

Fig. 17: Map of differential flux of wake ions in the $y-z$ plane of the LSwE coordinate system, showing the 5 locations of interest (enclosed by red rectangular boxes). Location 1 at $+E c$ limb, location 2 at $-E c$ limb, location 3 at $+y \operatorname{limb}$, and location 4 at $-y$ limb, and location 5 at the central wake. The locations 3 and 4 are in the plane containing solar wind velocity and IMF (Dhanya et al., 2016)

\section{Exploration of Venus}

\section{Surface and Interior}

Global scale geological mapping revealed the lithospheric evolution of Venus. A regional study by Kumar and Head (2013) showed an example for a complex network of several thousand kilometers long and few hundred kilometers wide extensional belts, which were associated with volcanism, through highresolution geological mapping of the Lada Terra region in Venus' southern hemisphere, using Magellan synthetic aperture radar images and ArcGIS. The geologic map of Lada Terra quadrangle (V-56) was prepared at a scale of 1:5,000,000. The map showed the distribution of various material units, primary and tectonic structures, and relative age relations between them.

\section{Atmosphere}

Bhardwaj and Jain (2012a) predicted the intensities of $\mathrm{N}_{2}$ triplet bands emissions on Venus, which can be observed by SPICAV experiment on the Venus Express mission.

\section{Studies on Other Planetary Bodies - Titan, Pluto, Comets and Vesta}

The $\mathrm{N}_{2}$ Vegard-Kaplan band model developed by 


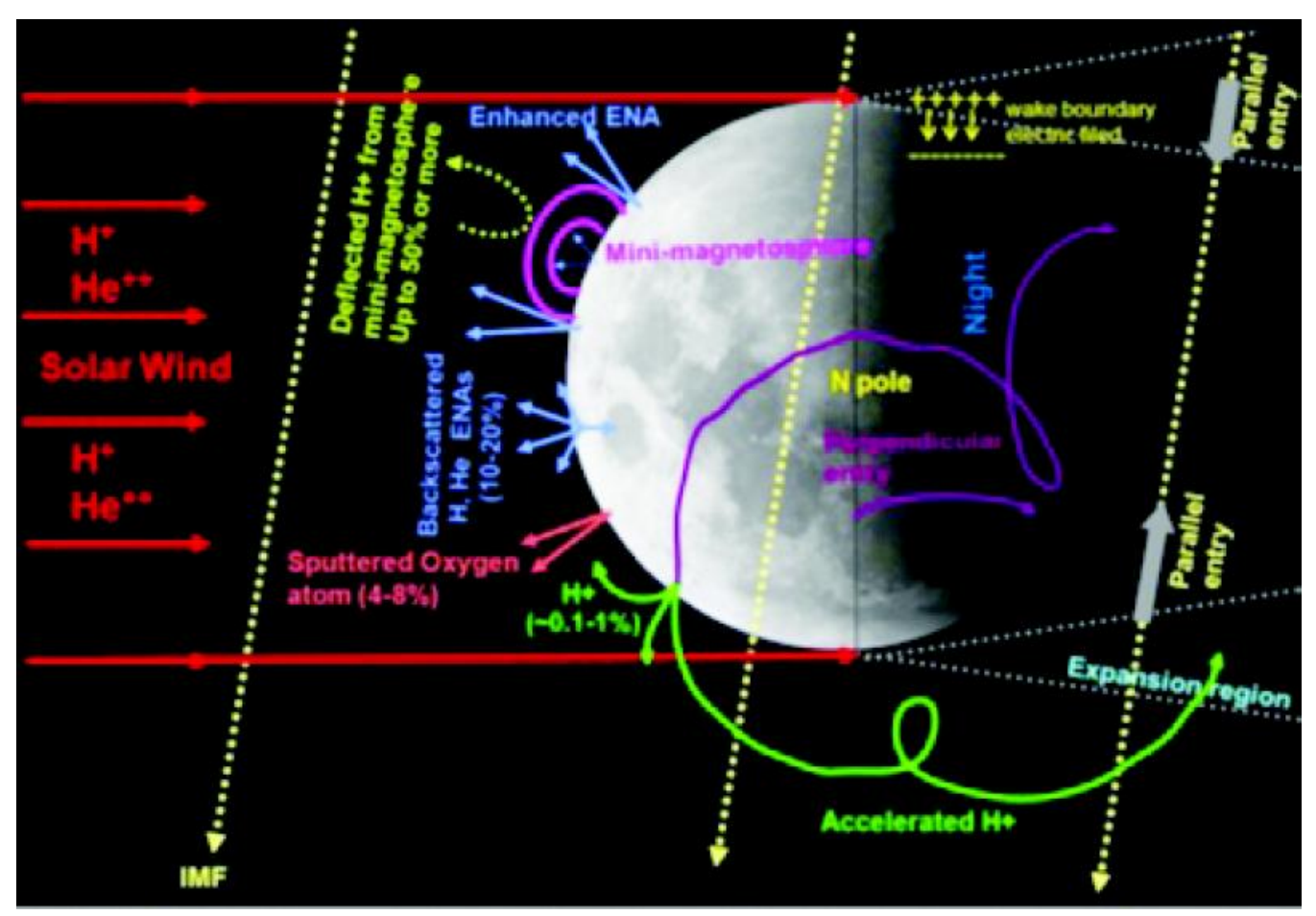

Fig. 18: A summary of our current understanding of the processes initiated by the interaction of solar wind with the Moon (Bhardwaj et al., 2015b)

Bhardwaj and coworkers has been used to successfully explain Cassini/UVIS measured UV emission on Titan: demonstrating that magnetospheric electron impact source is not required (Bhardwaj and Jain, 2012b). This model is used to make prediction for the ultraviolet emissions on Pluto for New Horizon fly-by of Pluto in 2015 (Jain and Bhardwaj, 2015). Bhardwaj and coworkers have developed a model of CO Cameronemissions in comets and predicted the intensity of Cameron band on comet 103P/Hartley, the target of November 5, 2010 encounter by NASA's EPOXI mission. This model has demonstrated that on comets the major production of CO Cameron band emission is photoelectron impact excitation of $\mathrm{CO}$ and not the photo-dissociative excitation of $\mathrm{CO}_{2}$ as assumed earlier for the past 20 years (Bhardwaj and Raghuram, 2012; Raghuram and Bhardwaj, 2012).

Bhardwaj and Raghuram (2012) have developed a coupled chemistry-emission model to study the production and loss mechanisms of the $\mathrm{O}\left({ }^{1} S\right)$ and $\mathrm{O}\left({ }^{1} D\right)$ atoms and the generation of red-doublet $(6300$, $6364 \AA$ ) and green $(5577 \AA$ ) lines in the coma of C/ 1996 B2 Hyakutake. The value of the intensity ratio of green to red-doublet (G/R ratio) of 0.1 has been used as a benchmark to identify the parent molecule of oxygen lines as $\mathrm{H}_{2} \mathrm{O}$. The model of Bhardwaj and Raghuram (2012) demonstrated that the $G / R$ ratio in cometary coma depends not only on photochemistry, but also on the projected area observed on the coma of a comet. This has helped provide the explanation for larger width of green line compared to red line on comets (Raghuram and Bhardwaj, 2013). In low gas production rate comets the $\mathrm{G} / \mathrm{R}$ ratio greater than 0.1 can be used to constrain the upper limit of $\mathrm{CO}_{2}$ abundance provided the slit-projected area on the coma is larger than the collisional zone (Raghuram and Bhardwaj, 2014).

Recently, this model has been applied to comet 67P/CHURYUMOV-GERASIMENKO, the target of Rosetta mission.The model calculations suggest that the electron impact reactions are the dominant sources in producing CO Cameron band emission. Hence, the observed CO Cameron emission intensity close to the cometary nucleus can be used to track the suprathermal electron intensity in the energy range of $10-15 \mathrm{eV}$ close to the nucleus. More recently, Monte Carlo model for electron degradation in methane $\left(\mathrm{CH}_{4}\right)$ and $\mathrm{Xenon}(\mathrm{Xe})$ gas has been developed; these models can be used for calculations of photoelectron and auroral or solar wind electron impact production 
rates and intensities of various emissions with application to Mars, Venus, and outer planets (Bhardwaj and Mukundan, 2015; Mukundan and Bhardwaj, 2016).

Processes Operating on Vesta Based on Study of Meteorites Originating from the Asteroid: Piplia Kalan Eucrite and Lohawat Howardite

Howardite, eucrite and diogenite (HED) type of meteorites represent the largest clan of achondrites and arepresumably derived from the differentiated asteroid 4-Vesta or Vesta-like asteroids. The Piplia Kalan eucrite, fell in Rajasthan, India on June 20, 1996 and the Lohawat achondrite, fell at Rajasthan, India on October 30, 1994 and were recovered and classified as having been originated in Vesta (Shukla A.D. et al., 1997; Sisodia et al., 2001). Earlier studies gave the first evidence of excess ${ }^{26} \mathrm{Al}$ in this meteorite, indicating that Vesta formed within $\sim 2$ million years of the formation of the solar system and ${ }^{26} \mathrm{Al}$ was a major heat source for volcanic activity and melting of this asteroid (Srinivasan et al., 1999). These meteorites have been recently studied in more detail by Basu Sarbadhikari et al. $(2015,2016)$ and Sisodia et al. (2015) to understand the processes involved in magmatic activity and impactor nature on the Vestan surface.

Piplia Kalan is an equilibrated, noncumulate basaltic eucrite and contains two distinct grain-sized

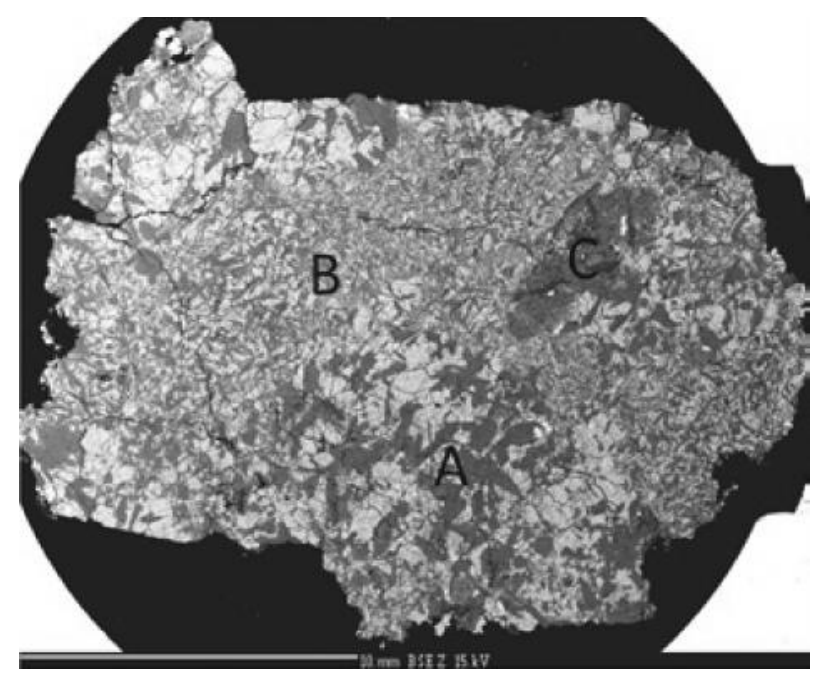

Fig. 19: Back-scattered electron image of a studied thicksection of Piplia-Kalan. Three well-characterized clasts (type-A, B and C) with their distinct but not very sharp margins igneous clasts; coarse (up to $3 \mathrm{~mm}$ ) and fine $(<0.1$ $0.5 \mathrm{~mm}$ with an average size $\sim 0.2 \mathrm{~mm}$ ). The coarse clast (type-A) displays dominantly ophitic-subophitic texture of blocky grains (Fig. 19). The finerclast (typeB) also has ophitic to sub-ophitic texture. Although rarely present in different sections of this eucrite a third clast (type-C) was also identified. Larger laths of plagioclase and silica surround the finer granular interlocking grains of granulitic texture (size 30-50 $\mu \mathrm{m})$. Type-C occurs as pockets intype-A, and at the boundary between type-A and type-B clasts. This study indicates multiple stages of early evolutionary history of Piplia Kalan. Type-A clast crystallized earliest at highly oxidized condition in the magma chamber in the deep crust, followed by fluid-induced metamorphism and metasomatism at similarly high fO2 (formation of type-C). Type-B formed from a relatively shallow magmatic flow in much-less fO2 than the earlier events. The final event was the granulite metamorphism of the whole mass of Piplia Kalan, presumably either by series of magmatism orimpact events, which took place in global-scale.

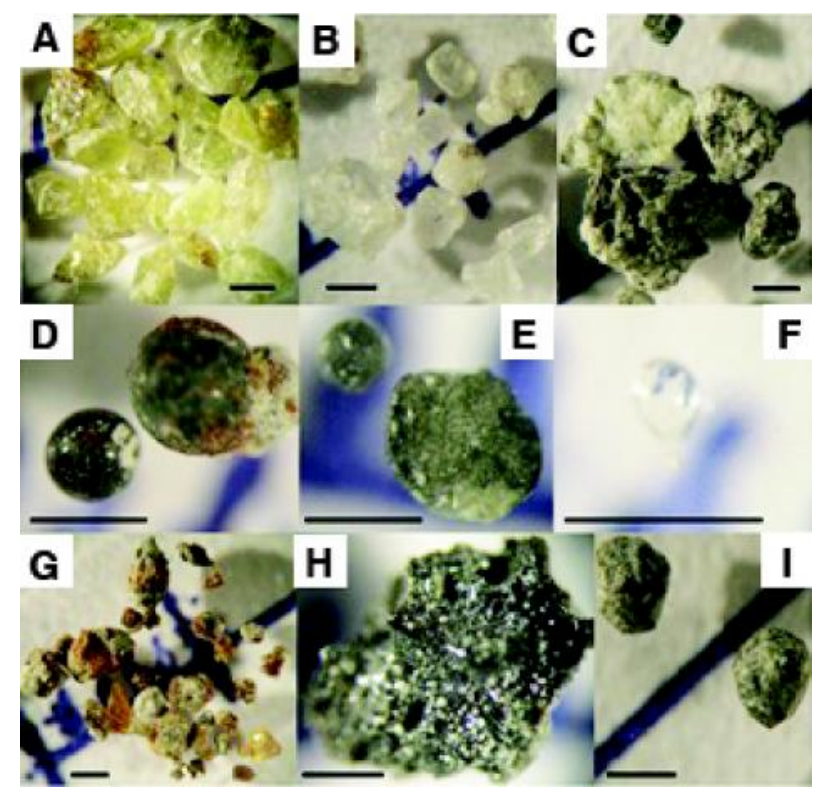

Fig. 20: Grain separates of Lohawat howardite which originated from the asteroid Vesta (A) pyroxene, (B) feldspar, (C) and i) Mg poor pyroxenes, (D) impact spherules, (E) chondrules, $(\mathrm{F})$ clear glass spherules, (G) regolith and (H) carbonaceous chondrite fragment. Scale bars are $1 \mathrm{~mm}$. Many of the grains exhibit solar wind effects showing that they were exposed on the surface of the asteroid 
Lohawat is a polymict breccia howardite, a mixture of eucrite and diogenites clasts and loosely boundregolith materials. Equilibration temperatures are $940 \pm 30^{\circ} \mathrm{C}$ for main-group type eucrite clasts and $830 \pm 30^{\circ} \mathrm{C}$ for cumulate eucrite clasts. REE abundance in diogenitic and regolith clasts, meltspherules and bulk sample indicates highly depleted nature of the diogenitic clasts. The glassyspherules are the most enriched in REEs and show a relatively large negative Eu-anomaly. Various degree of thermal metamorphism of the eucrite clasts indicates re-equilibration prior to their emplacement on the surface and before becoming part of the Lohawat howardite. Ninteen gases and nitrogen isotopes indicates that planetary type (Ne-HL) and solar wind (Ne-SW) trapped. Study of the noble gases have been made in several separated grains of Lohawat. The average cosmic ray exposure age of grains ranges from 25 to $224 \mathrm{Ma}$. The variability in exposure ages is because of the fact that different clastic and regolithic components of Lohawat suffered different duration of exposure to cosmic rays depending on their residence time as well as depth in the regolith. Carbonaceous chondrite type impactors were mixed in the pulverized matrix regoliths or in the melt spherules on the Vestan surface. These studies show a dynamic regolith in the early history of the regolith on Vesta.

\section{Future Indian Planetary Missions}

Following the success of Chandrayaan-1 and Mars Orbiter Mission (MOM), ISRO is planning for future planetary missions. Chandrayaan-2, which is a follow up mission of Chandrayaan-1 and will be carrying more advanced instruments to provide better information about several issues concerning evolution

\section{References}

Arya A S, Rajasekhar R P, Thangjam G, Ajai and Kiran Kumar A S (2011) Detection of potential site for future human habitability on the Moon using Chandrayaan-1 data Current Science 100 524-529

Arya A S et al. (2015a) Mars Colour Camera: the payload characterization/calibration and data analysis from Earth imaging phase Current Science 109

Arya A S et al. (2015b) Indian Mars-Colour-Camera captures far-side of the Deimos: A rarity among contemporary Mars of Moon. Most importantly, Imaging IR Spectrometer (IIRS) with the spectral region of 0.8 to $5 \mu \mathrm{m}$ will able to confirm the presence of $\mathrm{OH} / \mathrm{H}_{2} \mathrm{O}$ absorption features.Chandrayaan-2 will also have an orbiter, a lander and a rover for in-situ measurements. A repeat of TMC instrument is also planned. The proposed dual frequency SAR onboard Chandrayaan-2 will be a continuity of the S-band Mini SAR of Chandrayaan1 and will operate with both L- and S-bands, where L-band is expected to provide deeper penetration of the lunar regolith (Putrevu et al., 2016). The slantrange resolution will vary from $2 \mathrm{~m}$ to $75 \mathrm{~m}$, along with stand alone (L or S) and simultaneous (L and S) modes of imaging. It is planned to operate this instrument in hybrid and full-polarimetry mode with a wide range of imaging incidence angles $\left(\sim 10^{\circ}\right.$ to $\left.\sim 35^{\circ}\right)$. The high spatial resolution data obtained from MiniSAR on Chandrayaan-2 will greatly help in resolving ambiguities in interpreting high values of Circular Polarization Ratio (CPR) observed in MiniSAR data of Chandrayaan-1. Along with this, the full-polarimetric data will be better for detecting the presence (and estimating the quantity) of waterice in the polar craters. The orbiter also has an experiment for radio science called RAMBHA Dual Frequency Radio Science (DFRS) experiment. The CHACE-2 experiment on the Chandrayaan-2 orbiter will greatly help in improving our understanding of the lunar exospheric composition and distribution and its diurnal and seasonal variability. The science instruments on Chandrayaan-2 Lander are ChaSTE (Chandra's Surface Thermo-physical Experiment), RAMBHA-Langmuir Probe, a Seismometer, and RAMBHA-DFRS. Discussions are going on to give shape to the second Mars mission and a possible mission to Venus.

orbiters Planetary and Space Science http://dx.doi.org/ 10.1016/j.pss.2015.08.018

Barabash S, Bhardwaj A, Wieser M, Sridharan R et al. (2009) Investigation of the solar wind - Moon interaction onboard Chandrayaan-1 mission with the SARA Experiment Current Science 96 526-534

Basu Sarbadhikari A (2015) Petrographical and Mineralogical Diversity between Fresh and Impact-Melted Domains of Olivine-Phyric Shergottite Tissint. In $46^{\text {th }}$ Lunar and Planetary Science Conference, Houston Texas, Abstract \# 
1456

Basu Sarbadhikari A, Babu E V S S K and Vijaya Kumar T (2016) Olivine-Hosted Melt-Inclusions in Martian Meteorite Tissint In $47^{\text {th }}$ Lunar and Planetary Science Conference, Houston Texas, Abstract \#1836

Basu Sarbadhikari A, Sisodia M S and Bhandari N (2015) Geochemistry of texturally different fractions of Piplia Kalan Eucrite and Lohawat Howardite In 46th Lunar and Planetary Science Conference, Houston, Texas, USA. Abstract \# 1464

Basu Sarbadhikari A, Mahajan R R, Sisodia M S, Babu E V S S K, Vijaya Kumar T, Shyam Prasad M and Bhandari N (2016) Multiple Stages of Early Evolution of Heterogeneous Type7Piplia Kalan Eucrite. In $47^{\text {th }}$ Lunar and Planetary Science Conference, Houston Texas Abstract \#1841

Bhandari N and Srivastava N (2014) Active moon: evidences from Chandrayaan-1 and the proposed Indian missions Geoscience Letters 1

Bhardwaj A, Wieser M, Dhanya M B, Barabash S, Yoshifumi F, Holmström M, Sridharan R, Wurz P, Schaufelberger A and Kazushi A (2010) The Sub-keV Atom Reflecting Analyzer (SARA) Experiment Aboard Chandrayaan-1 Mission: Instrument and Observations Advances in Geosciences 19 $151-162$

Bhardwaj A and Jain S K (2012a) Calculations of $\mathrm{N}_{2}$ triplet states vibrational populations and band emissions in Venusian dayglow Icarus 217 752-758

Bhardwaj A and Jain S K (2012b) Production of $\mathrm{N}_{2}$ VegardKaplan and other triplet band emissions in the dayglow of Titan Icarus 218 989-1005

Bhardwaj A and Raghuram S (2012) Coupled chemistry-emission model for atomic oxygen green and red-doublet emissions in comets: Acase study for the comet C/1996 B2 Hyakutake Astrophysical Journal 74818

Bhardwaj A and Mukundan V (2015) Monte Carlo model for electron degradation in methane gas Planetary and Space Science 111 34-43

Bhardwaj A et al. (2015a) MENCA experiment aboard India's Mars Orbiter Mission Current Science 109

Bhardwaj A, Dhanya M B, Alok A, Barabash S, Wieser M, Futaana Y, Wurz P, Vorburger A, Holmstrom M, Lue C, Harada Y and Asamura K (2015b) A New View on the Solar wind interaction with the Moon Geoscience Letters 2 1-15

Bhardwaj A et al. (2016) On the evening time exosphere of Mars: Result from MENCA aboard Mars Orbiter Mission Geophysical Research Letters $\mathbf{4 3}$ doi:10.1002/ 2016GL067707
Bhattacharya A, Porwal A, Dhingra S and Venkataraman S De G (2015) Remote estimation of dielectric permittivity of lunar surface regolith using compact polarimetric synthetic aperture radar data Advances in Space Research 562439 2448

Bhattacharya S, Chauhan P and Ajai (2012a) Discovery of olivineorthopyroxene-spinel assemblage from the lunar near side using Chandrayaan-1 Moon Mineralogy Mapper $\left(\mathrm{M}^{3}\right)$ data Current Science 103 21-22

Bhattacharya S, Jain N, Chauhan P, Parthasarathy G and Ajai (2012b) Study of hydrous sulfates from the Decaan province (DVP) of Kutch, India: implications for aqueous alteration processes on Mars $43^{\text {rd }}$ LPSC Abstract 1468

Bhattacharya S, Saran S, Dagar A, Chauhan P, Chauhan M, Ajai and Kiran Kumar A S (2013) Endogenic water on the Moon associated with non-mare silicic volcanism: implications for hydrated lunar interior Current Science $\mathbf{1 0 5}$

Bhattacharya S, Lal D, Chauhan M, Chauhan P, Ajai and Kiran Kumar A S (2015a) Detection of hydroxyl-bearing exposures of possible magmatic origin on the central peak of crater Theophilus using Chandrayaan-1 Moon Mineralogy Mapper $\left(\mathrm{M}^{3}\right)$ data Icarus 260 167-173

Bhattacharya S, Chauhan M and Chauhan P (2015b) Remote detection of magmatic water in association with Olivine of possible mantle origin on the moon $46^{\text {th }}$ LPSC, Abstract 1396

Bhattacharya S, Mitra S, Gupta S, Jain N, Chauhan P, Parthasarathy G and Ajai (2016) Jarosite occurrence in the Deccan Volcanic Province of Kachchh, western India: Spectroscopic studies on a Martian analog locality Journal of Geophysical Research Planets 121 doi:10.1002/ 2015JE004949

Colaprete A et al. (2010) Detection of water in the LCROSS ejecta plume Science 330 463-468

Chauhan P, Kaur P, Ajai, Kiran Kumar AS (2012) Lunar geosciences using Chandrayaan-1: Indian perspective Proceedings of Indian National Science Academy 78 239-247

Chauhan P, Kaur P, Bhattacharya S, Dagar A, Ajai and Kiran Kumar A S (2014) Detection of $\mathrm{OH} / \mathrm{H}_{2} \mathrm{O}$ on the central peak of Jackson crater from Moon Mineralogical Mapper $\left(\mathrm{M}^{3}\right)$ onboard Chandrayaan-1 45 th LPSC, Abstract 2072

Chauhan P et al. (2015) Hyperspectral remote sensing of planetary surfaces: an insight into composition of inner planets and small bodies in the solar system Current Science 108

Chauhan M, Bhattacharya S, Saran S, Chauhan P and Dagar A (2015) Compton-Belkovich Volcanic Complex (CBVC): An ash flow caldera on the Moon Icarus 253 115-129 
Clark R N (2009) Detection of adsorbed water and hydroxyl on the Moon Science 326 562-564

Das T P, Thampi S V, Bhardwaj A, Ahmed S M and Sridharan R (2016) Observation of Neon at mid and high latitudes in the sunlit lunar exosphere: Results from CHACE aboard MIP/Chandrayaan-1 Icarus 272 206-211

Dhanya M B, Bhardwaj A, Futaana Y, Holmstrom M, Barabash S, Wieser M Fatemi S, Wurz P, Alok A and Thampi R S (2013) Proton entry into the near-lunar plasma wake for magnetic field aligned flow Geophysical Research Letters 40 2913-291

Dhanya M B, Bhardwaj A, Futaana Y, Barabash S, Alok A, Wieser M, Holmstrom M, Wurz P (2016) Characteristics of proton velocity distribution functions in the near-lunar wake from Chandrayaan-1/SWIM observations Icarus 271 120-130

Futaana Y, Barabash S, Wieser M, Homlström M, Lue C, Wurz P, Shaufelberger A, Bhardwaj A, Dhanya M B and Asamura K (2012) Empirical Energy Spectra of Neutralized Solar Wind Proton from the Lunar Regolith Journal of Geophysical Research 117 E05005

Goswami J N and Annadurai M (2009) Chandrayaan 1: India's first planetary science mission to the moon Current Science 96 486-491

Greenberger R N, Mustard J F, Senthil Kumar P, Dyar M D, Breves E A and Sklute E C (2012) Low temperature aqueous alteration of basalt: Mineral assemblages of Deccan basalts and implications for Mars Journal of Geophysical Research Planets 117 E00J12, doi:10.1029/2012JE004127

Gupta R P, Srivastava N and Tiwari R K (2014) Evidences of relatively new volcanic flows on the Moon Current Science 107

Harada Y, Futaana Y, Barabash S, Wieser M, Wurz P, Bhardwaj A, Asamura K, Saito Y, Yokota S, Tsunakawa H and Machida S (2014) Backscattered Energetic Neutral Atoms from the Moon in the Earth's plasma sheet observed by Chandarayaan-1/Sub-keV Atom Reflecting Analyser instrument Journal of Geophysical Research Space Physics $1191-12$

Jain N, Bhattacharya S, Chauhan P and Ajai (2012) Hyperspectral study of hydrous magnesium minerals (Serpentine) from ultramafic rocks along the Rikhabhdev lineament, Rajasthan, India as an analogue for hydrous magnesium minerals on Mars 43 ${ }^{\text {rd }}$ LPSC Abstract 1474

Jain N and Chauhan P (2014) Aqueous minerals from ArsiaChasmata of Arsia Mons, Tharsis region: implications for aqueous alteration processes on Mars $45^{\text {th }}$ LPSC Abstract 1826
Jain N and Chauhan P (2015a) Study of phyllosilicates and carbonates from the Capri Chasma region of Valles Marineris on Mars based on Mars Reconnaissance OrbiterCompact Reconnaissance Imaging Spectrometer for Mars (MRO-CRISM) observations Icarus 7-17

Jain N and Chauhan P (2015b) Identification of deposits of aqueous minerals in northern part of Hellas Planitia region on Mars Using MRO-CRISM: implications for past aqueous history of Mars $46^{\text {th }}$ LPSC Abstract 1838

Jain S K and Bhardwaj A (2011) Model calculation of $\mathrm{N}_{2}$ VegardKaplan band emissions in Martian dayglow Journal of Geophysical Research 116 E07005

Jain S K and Bhardwaj A (2012) Impact of solar EUV flux on CO Cameron band and $\mathrm{CO}_{2}^{+} \mathrm{UV}$ doublet emissions in the dayglow of Mars Planetary and Space Science 63-64 110122

Jain S K and Bhardwaj A(2015) Production of $\mathrm{N}_{2}$ Vegard-Kaplan and Lyman-Birge-Hopefield emissions on Pluto Icarus 247 285-290

JPL (2015) Planetary Satellite Physical parameters (Solar System Dynamics) <http://ssd.jpl.nasa.gov/?sat_phys_par>

Kaur P, Chauhan P, Bhattacharya S, Ajai and Kiran Kumar A S (2012) Compositional diversity at Tycho crater: Mg-spinel exposures detected from Moon Mineralogical Mapper $\left(\mathrm{M}^{3}\right)$ data $43^{\text {rd }}$ LPSC Abstract 1434

Kaur P, Chauhan P and Ajai (2013a) Exposures of Mg-spinel on an evolved silicic lithology Hansteen Alpha on the Moon $44^{\text {th }}$ LPSC Abstract 1348

Kaur P, Chauhan P and Ajai (2013b) Detection of Mg-Spinel Exposures from the Anorthositic Terrain Surrounding Mare Ingenii on the Far Side of the Moon 44th LPSC Abstract 1547

Kaur P and Chauhan P (2014) Detection of spinels exposures from some near side locations of the Moon $45^{\text {th }}$ LPSC Abstract 2059

Kumar P S, Keerthi V, Kumar A S, Mustard J F, Krishna B G, Amitabh Ostrach L R, Kring D A, Kiran Kumar A S and Goswami J N (2013) Gullies and landslides on the Moon: Evidence for dry-granular flows Journal of Geophysical Research Planets 118 206-223 doi:10.1002/jgre.20043

Kumar P S and Head J W (2013) Geologic map of the Lada Terra (V-56) quadrangle, Venus, US Geological Survey Scientific Investigations Map 3246, scale 1:5,000,000, 11 p., http:/ /dx.doi.org/10.3133/sim3249

Kumar P S et al. (2014) Impact fragmentation of basalt at Lonar Crater, India: Implications for impact cratering processes in basalt Journal of Geophysical Research: Planets 119 
2029-2059 DOI:10.1002/2013JE004543

Kumar P S et al. (2016) Recent shallow moonquake and impacttriggered boulder falls on the Moon: New insights from the Schrödinger basin Journal of Geophysical Research Planets 121 147-179 doi:10.1002/ 2015JE004850

Krishna N and Kumar P S (2016) Impact spallation processes on the Moon: A case study from the size and shape analysis of boulders and secondary craters of Censorinus Crater Icarus 264 274-299

Lal D, Chauhan P, Shah R D, Bhattacharya S, Ajai and Kiran Kumar A S (2012) Detection of Mg-spinel lithologies on central peak of crater Theophilus using Moon Mineralogy Mapper $\left(\mathrm{M}^{3}\right)$ data from Chandrayaan-1 Journal of Earth System Sciences 121 847-853

Lue C, Futaana Y, Wieser M, Barabash S, Bhardwaj A, Wurz P (2014) Chandrayaan-1 observations of backscattered solar wind protons from the lunar regolith: Dependence on solar wind velocity Journal of Geophysical Research Planets 119 968-975

Lue C, Futaana Y, Barabash S, Saito Y, Nishino M, Wieser M, Asamura K, Bhardwaj A and Wurz P (2016) Scattering characteristics and imaging of energetic neutral atoms from the Moon in the terrestrial magnetosheath Journal of Geophysical Research $121432-445$

Mathew K et al. (2015) Methane Sensor for Mars Current Science 109

Melosh H J (1989) Impact Cratering: A Geologic Process Oxford Monographs on

Geology and Geophysics, Oxford Univ. Press, New York

Mishra M K, Chauhan P, Singh R, Moorthi S M and Sarkar S S (2016) Estimation of Dust Variability and Scale Height of Atmospheric Optical Depth (AOD) in the Valles Marineris on Mars by Indian Mars Orbiter Mission (MOM) data Icarus 265 84-94

Mukherjee S and Singh P (2015) Identification of tectonic deformations on the south polar surface of the moon Planetary and Space Science 112 46-52

Mukundan V and Bhardwaj A (2016) Monte Carlo model for electron degradation in Xenon Proceedings of Royal Society A 472 (2187)

Pieters C M et al. (2009) Character and spatial distribution of $\mathrm{OH} / \mathrm{H}_{2} \mathrm{O}$ on the surface of the Moon seen by $\mathrm{M}^{3}$ on Chandrayaan-1 Science 326 568-571

Putrevu D, Das A, Vachhani J G, Trivedi S and Misra T (2016) Chandrayaan-2 dual-frequency SAR: Further investigation into lunar water and regolith Advances in Space Research $57627-646$
Raghuram S and Bhardwaj A (2012) Model for the Production of CO Cameron band emission in Comet 1P/Halley Planetary and Space Science 63-64 139-149

Raghuram S and Bhardwaj A (2013) Model for Atomic Oxygen Visible Line Emissions in Comet C/1995 O1 Hale-Bopp Icarus 223 91-104

Raghuram S and Bhardwaj A (2014) Photochemistry of atomic oxygen green and red-doublet emissions in comets at larger heliocentric distances Astronomy and Astrophysics 566(A134) 1-11

Schaufelberger A, Wurz P, Barabash S, Wieser M, Futaana Y, Holmstrom M, Bhardwaj A, Dhanya M B, Sridharan R and Asamura K (2011) Scattering function for energetic neutral hydrogen atoms off the lunar surface Geophysical Research Letters 38 L22202

Shukla AD et al. (1997) Met Planet Sci 32 611-615

Singh R and Mishra M K (2016) Identification of Dust Storm and Dust Devil on Mars using Mars Colour Camera onboard Mars Orbiter Mission $19^{\text {th }}$ National Space Science Symposium, SPL, Trivandrum

Singh R P et al. (2015). Thermal Infrared Imaging Spectrometer for Mars Orbiter Mission Current Science 109

Sinha R K and Murty S V S (2013a) Geomorphic signatures of glacial activity in the Alba Patera volcanic province: Implications for recent frost accumulation on Mars Journal of Geophysical Research 118 1609-1631 doi:10.1002/ jgre.20113

Sinha R K and Murty S V S (2013b) Evidence of extensive glaciation in Deuteronilus Mensae, Mars: Inferences towards multiple glacial events in the past epochs Planetary and Space Science $\mathbf{8 6}$ 10-32

Sinha R K and Murty S V S (2015) Amazonian modification of Moreux crater: Record of recent and episodic glaciation in the Protonilus Mensae region of Mars Icarus 245 122144

Sisodia M S, Shukla A D, Suthar K M, Mahajan R R, Murty S V S, Shukla P N, Bhandari N and Natarajan R (2001) The Lohawat howardite: mineralogy, chemistry and cosmogenic effects Meteoritics \& and Planetary Science 361457-1466

Smitha V T, Sridharan R, Das T P, Ahmed S M, Kamlakar J and Bhardwaj A (2015) The spatial distribution of molecular hydrogen in the lunar atmosphere: New Results Planetary and Space Science 106 142-147

Sridhar R V L N et al. (2015) Lyman Alpha Photometer: a farultraviolet sensor for the study of hydrogen isotope ratio in the Martian exosphere Current Science 109

Sridharan R, Ahmed S M, Das T P et al. (2010) 'Direct' evidence 
for water $\left(\mathrm{H}_{2} \mathrm{O}\right)$ in the sunlit lunar ambience from $\mathrm{CHACE}$ on MIP of Chandrayaan-1 Planetary and Space Science 58 947-950

Sridharan R, Das T P, Ahmed S M, Supriya G, Bhardwaj A and Kamalakar J A (2013) Spatial heterogeneity in the radiogenic activity of the lunar interior: Inferences from CHACE and LLRI on Chandrayaan-1 Advances in Space Research 51 168-178

Srinivasan G Goswami J N and Bhandari N (1999) 26Al in eucrite Piplia Kalan: plausible heat source and formation chronology of eucritic parent bodies Science 284 13481350

Srivastava N and Gupta R P (2012) "Compositional diversity inside Lowell crater, Orientale Basin: Evidences for extensive spinel rich deposits", $2^{\text {nd }}$ Conf. on Lunar Highland Crust, Bojeman, Montana, 9016.pdf

Srivastava N and Gupta R P (2013) "Spatial distribution of spinel in the orientale basin: new insights from M3 Data", $44^{\text {th }}$ Lunar and Planetary Science Conference, Houston, 1509. pdf

Srivastava N, Kumar D and Gupta R P (2013) Young viscous flows in the Lowell crater of Orientale basin, Moon: Impact melts or volcanic eruptions? Planetary and Space Science 87 37-45

Srivastava N and Varatharajan I (2016) Geomorphology of Lowell crater region on the Moon Icarus 266 44-56

Sruthi U and Kumar S P (2014) Volcanism on farside of the Moon: New evidence from Antoniadi in South Pole Aitken basin Icarus 242 249-268

Sunshine J M et al. (2009) Temporal and spatial variability of lunar hydration as observed by the Deep Impact Spacecraft Science 326 565-568
Spudis P D et al. (2010) Initial results for the North Pole of the Moon from Mini-SAR, Chandrayaan-1 mission Geophysical Research Letters 37 L06204

Thampi S V, Sridharan R, Das T P, Ahmed S M, Kamalakar J A and Bhardwaj A (2015) The spatial distribution of molecular Hydrogen in the lunar atmosphere -New results Planet Space Sci 106 142-147

Varatharajan I, Srivastava N and Murty S V S (2014) Mineralogy of young lunar mare basalts: Assessment of temporal and spatial heterogeneity using $\mathrm{M}^{3}$ data from Chandrayaan-1 Icarus 236 56-71 doi: 10.1016/j.icarus.2014.03.045

Vijayan S, Mohan S and Murty S V S (2015) Lunar regolith thickness estimation using dual frequency microwave brightness temperature and influence of vertical variation of $\mathrm{FeO}+\mathrm{TiO}_{2}$ Planetary and Space Science 105 123-132

Vorburger A, Wurz P, Barabash S, Wieser M, Futaana Y, Lue C, Holmstrom M, Bhardwaj A, Dhanya M B and Asamura K (2013) Energetic Neutral Atom Imaging of the Lunar Surface Journal of Geophysical Research 118 3937-3945

Vorburger A, Wurz P, Barabash S, Wieser M, Futaana Y, Holmstrom M, Bhardwaj A and Asamura K (2014) First Direct Observation of Sputtered Lunar Oxygen $J$ Geophysical Research 119 1-14

Vorburger A, Wurz P, Barabash S, Wieser M, Futaana Y, Bhardwaj A and Asamura K (2015) Imaging the South Pole - Aitken Basin in Backscattered Neutral Hydrogen Atoms Planetary and Space Science 115 57-63

Wieser M, Barabash S, Futaana Y, Holmström M, Bhardwaj A, Sridharan R, Dhanya M B, Wurz P, Schaufelberger A and Asamura K (2010) First observation of a minimagnetosphere above a lunar magnetic anomaly using energetic neutral atoms Geophysical Research Letters 37 L05103. 